\title{
Synthesis of single and interplant non-isothermal water networks
}

\author{
Nidret Ibrić ${ }^{*}, 1$, Elvis Ahmetović ${ }^{1}$, Zdravko Kravanja $^{2}$, François Maréchal $^{3}$, Maziar Kermani ${ }^{3}$
}

${ }^{1}$ Faculty of Technology, University of Tuzla, Tuzla, Bosnia and Herzegovina e-mail: nidret.ibric@untz.ba, elvis.ahmetovic@untz.ba

\author{
${ }^{2}$ Faculty of Chemistry and Chemical Engineering, University of Maribor, Maribor, Slovenia \\ e-mail: zdravko.kravanja@um.si \\ ${ }^{3}$ EPFL/Industrial Processes \& Energy Systems Engineering Group (IPESE), Sion, Switzerland \\ e-mail: francois.marechal@epfl.ch, maziar.kermani@epfl.ch
}

\begin{abstract}
This paper addresses the synthesis problem of non-isothermal water networks using a mathematical programming approach. A heat-integrated water network superstructure and its corresponding mixed integer nonlinear programming (MINLP) model is proposed for the synthesis of individual as well as interplant water networks. A new feature of the proposed model includes piping installation cost within the objective function minimizing the total annual cost of the network. This introduces additional tradeoffs between operating and investment costs that can impact a final network design. Three examples were solved in order to demonstrate the applicability and effectiveness of the proposed model and solution approach. The results show that additional saving in total annual cost can be achieved by enabling direct water integration between plants. Improved solutions were obtained compared to those reported in the literature considering freshwater and utilities consumption as well as total annual cost.
\end{abstract}

\section{KEYWORDS}

Interplant water network, non-isothermal water network, water and heat integration.

\footnotetext{
* Corresponding author: Nidret Ibrić. Postal address: Univerzitetska 8, 75000 Tuzla, Bosnia and Herzegovina. Phone: +387 35 320761; Fax: +387 35 320741; E-mail address: nidret.ibric@untz.ba
} 


\section{INTRODUCTION}

The efficient usage of natural resources is an important goal for achieving profitability as well as sustainability of industrial processes. The role of industrial water is especially important where it can be used for different purposes such as process water, cooling water, water for energy production etc.

Consumption of water and energy is related to each other e.g. water is required for energy production and energy is required for many water related industrial processes such as water transportation, wastewater treatment, heating and cooling etc. Savings in water consumption in industrial processes can be achieved by using holistic approaches based on Energy and Water Quality Management System (EWQMS) (Cherchi et al., 2015) on the operational level. In addition, on the retrofit or design level Process Integration techniques can be used, such as Pinch Analysis (PA) (Savulescu et al., 2005) and Mathematical Programming (MP) (Bagajewicz et al., 2002) that can be applied for batch (Majozi et al., 2006) and continuous processes (Bogataj and Bagajewicz, 2008). However, a combination of approaches can be used consisting of water audit, PA and process application in order to systematically identify water conservation opportunities (Agana et al., 2013).

Research related to efficient utilisation of natural resources and development and application of systematic tools have been popular research areas for more than forty years (Klemeš and Kravanja, 2013). During that time the scope of resource conservation networks (i.e. heat exchanger networks or water networks) has changed from integration of local sites (single-plant), towards integration of interplant networks and total site integration (Klemeš et al., 2013). This expands the integration potential for resource conservation, enabling additional savings in resource consumption. Chemical production sites can have a large number of water-using units (Olesen and Polley, 1996) that are usually grouped in different locations within the industrial complex.

A consideration of geographical location of process water-using units when synthesising water networks has been addressed in past (Olesen and Polley, 1996). By applying the water targeting procedure (Wang and Smith, 1994) to the overall site and to the geographically decomposed group of units the water reuse opportunities between units at different locations can be identified. Using Water Cascade Analysis (WCA) (Manan et al., 2004) water reuse opportunities were first analysed within individual plants and afterwards a cross-plant water integration possibilities were investigated (Foo, 2008) enabling significant reduction of freshwater consumption. The targeting procedure based on PA for a single water network has been expanded into a linear programming (LP) optimisation based technique for interplant water integration (Chew and Foo, 2009). Thus, the minimum freshwater and cost targets (cost of interplant piping) for the interplant water network can be set prior to the network design. A novel integration scheme including centralised (between different plants) and decentralised (within individual plants) water mains was proposed (Chen et al., 2010). A corresponding model was formulated as a mixed integer nonlinear programming (MINLP) and solved for two scenarios including minimising freshwater consumption and minimising total annual cost (TAC). 
These papers addressed only water integration options within and between plants assuming fixed temperature of water streams. However, in most cases, different process water-using units operate at different temperatures, and wastewater discharged into the environment has to satisfy regulations regarding not only contaminant concentration but also the effluent temperature. Therefore, some water streams will require heating or cooling demands. Accordingly, it is possible to integrate hot and cold water streams in order to minimise utilities consumption. For this reason, the objective is to minimise not just freshwater consumption but rather perform simultaneous optimisation of freshwater and energy consumption. This synthesis problem is known in the literature as the synthesis of non-isothermal water network, a heat integrated water network or a water allocation and heat exchange network.

Recent review paper (Ahmetović et al., 2015) presented a systematic and comprehensive literature review of studies within this field over the last two decades as well as possible future research directions. To the best of our knowledge, only a few papers address the issue of simultaneously synthesising heatintegrated interplant water networks. Authors firstly addressed the synthesis problem for fixed flow rate processes (Zhou et al., 2012a) and later expanding their research to fixed contaminant-load processes (Zhou et al., 2012b). The proposed approach is based on the multi-scale state-space superstructure and corresponding MINLP model. The direct and indirect integration schemes were analysed along with their impact on network design and TAC that included a cross plant piping installation cost. In an industrial pulp and paper case study (Kermani et al., 2016b), the total site is divided into four locations due to geographical constraints. Heat integration between these locations is favoured through the water network only (water streams act as heat transfer medium between locations). However they did not consider piping cost of the water network. The established superstructure for simultaneous optimization of water and energy has been later extended to address inter-plant operations (Kermani et al., 2016a). In order to synthesise a non-isothermal water network trade-offs between water and energy cost and investment costs should be simultaneously explored. The piping cost has been rarely addressed within the studies in the literature (Leewongtanawit and Kim, 2008). However it is important to highlight that besides investment cost of heat exchangers and wastewater treatment units, piping cost can have influence on the final network design. As a result, less complex and more practical design can sometimes be obtained. The reader is referred to recent studies for more information about water and energy interactions (Varbanov, 2014) and industrial water use (Klemeš, 2012), as well as the comprehensive literature review of non-isothermal water network synthesis (Ahmetović et al., 2015).

The aim of this paper is to present a Mathematical Programming (MP) approach for the synthesis of single and interplant non-isothermal water networks. A recently proposed MINLP model (Ibrić et al., 2016) was modified by introducing binary parameters for identifying process units, wastewater treatment units and hot/cold streams within different plants and removing restricted connection between the units within different plants. This modified model enables the synthesis of interplant water networks, simultaneously exploring different water and heat integration opportunities. In addition, a piping cost is included within the objective function minimising the TAC of the network. In the proposed approach 
piping cost is accounted for by using economic pipe diameter for which the pumping cost is minimum, and thus the trade-off exist between investment in pipe and its operating cost for water transportation.

\section{PROBLEM STATEMENT}

Given a sets of freshwater sources $s \in S F W$, process water-using units $p \in P U$, wastewater treatment units $t \in T U$, the objective is to find an optimal design of the non-isothermal water network minimising operating cost (freshwater, utilities and wastewater treatment) and investment cost (heat exchangers, wastewater treatment units and pipes) of the network.

The following common assumptions were adopted within the synthesis problem:

- The same water source at given temperature and contaminant concentration level is available for all the plants within the industrial complex

- The existence of connections in interplant problems are defined ahead of the synthesis and are therefore not optimized

- The process water-using units operate assuming fixed temperature fixed mass load of contaminants transferred to the water stream entering the unit

- Treatment units operate at fixed temperature and fixed removal ratio of the contaminants

- Water heat capacity is constant $(4.2 \mathrm{~kJ} /(\mathrm{kg} \mathrm{K}))$ and independent of the streams temperature

- Individual heat transfer coefficients of water streams and utilities are constant

- Single hot and cold utilities are available

- Water streams are at fixed temperature (no heat losses) with variable heat capacity flow rate

- Fixed effluent temperature.

The goal of the synthesis problem is to determine the optimum design of a non-isothermal water network satisfying the given constraints and exploring mass and heat exchange opportunities within and between different plants.

\section{SUPERSTRUCTURE REPRESENTATION}

Fig.1 shows a conceptual superstructure of an interplant heat-integrated water network involving two plants. A recently proposed compact superstructure (Ibrić et al., 2016) for individual plants has been modified in order to account for location of heating and cooling stages required for piping cost calculation as well as to represent connections between units within different plants.

Each individual water network consists of two networks, namely, water and wastewater treatment network (WN-WTN) and a heat exchange network (HEN). The first network (WN-WTN) enables water integration opportunities (water reuse, regeneration reuse and regeneration recycling) between waterusing units $(p \in P U)$ and wastewater treatment units $(t \in T U)$. The second network (HEN) enables heat exchange opportunities (non-isothermal mixing of water streams at different temperatures and heat exchange through heat exchangers). Both networks WN-WTN and HEN are interconnected enabling interactions between them. Note that the same individual superstructure applies to each plant. The 
connections between networks of different plants are represented by dashed lines, shown in Fig. 1. These connections are crucial in defining water and heat integration opportunities between different plants. Note that a separate set of plants is not defined but the whole interplant network is observed as a complex individual plant. The superstructure units of different plants were identified by using binary parameters. This reduces the model size enabling easier solution of the non-isothermal interplant water network problem. Therefore, the final structure of interplant problems is determined through continuous optimization of flows between plants. It is assumed that plants are placed within the same industrial complex and the same freshwater sources $s \in S F W$, and hot/cold utilities are used for each plant. Also, the wastewater sink (discharge place) is common to all plants.

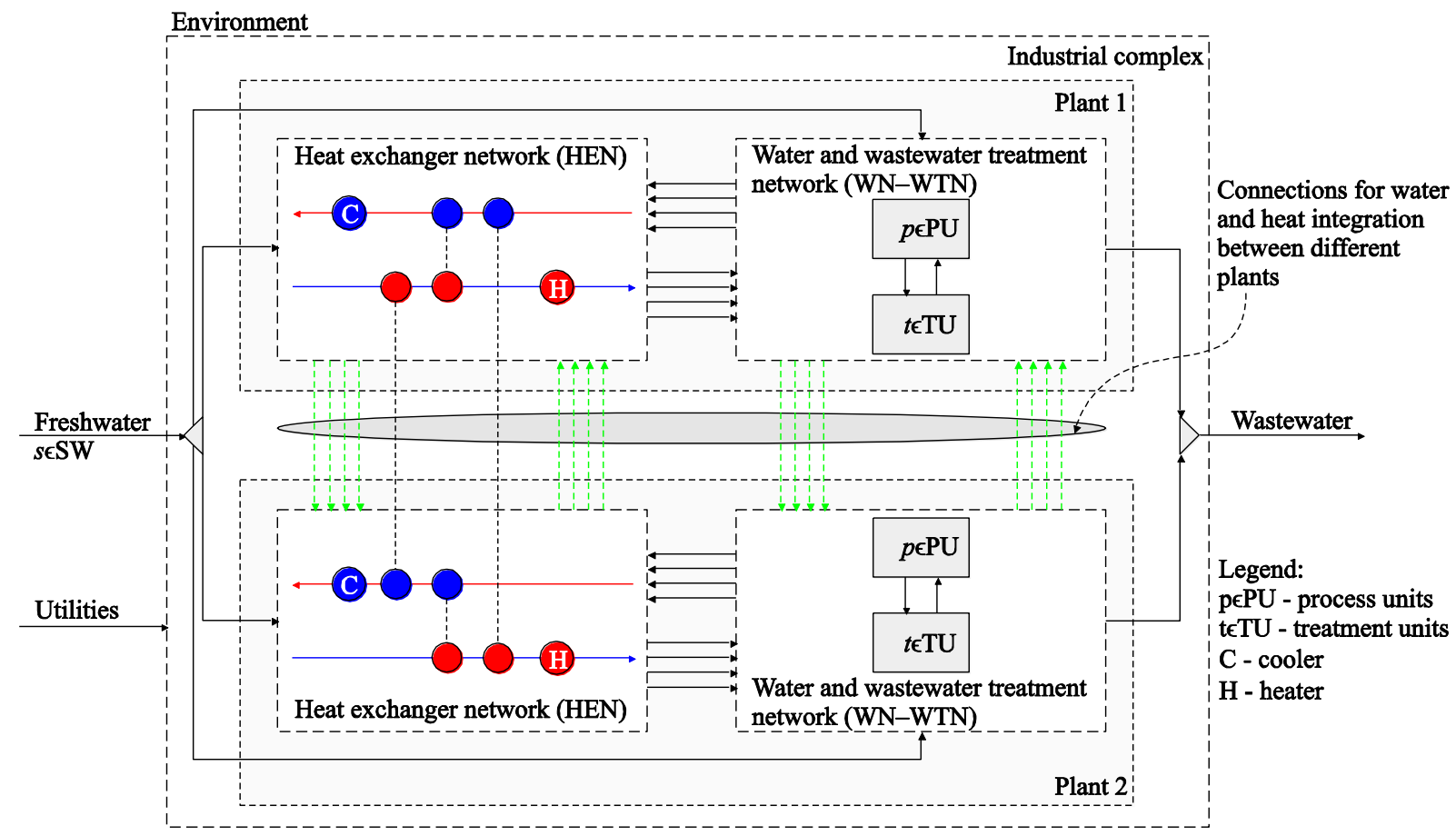

Fig. 1. A conceptual superstructure representation of a non-isothermal water network including two plants.

Fig. 2 shows a detailed representation of the individual water network superstructure based on the previously developed superstructure (Ibrić et al., 2016). However, the superstructure has been modified in order to relate the location of heating and cooling stages for freshwater and wastewater streams with the location of process water-using units. It consists of:

- Freshwater sources $s \in S F W$,

- Process water-using units $p \in P U$ with corresponding one hot streams cooling stage and one cold streams heating stage at the location of process unit $p$,

- Wastewater treatment units $t \in T U$ and

- A final wastewater mixer (wastewater discharge). All superstructure elements are interconnected enabling water and heat integration options. 


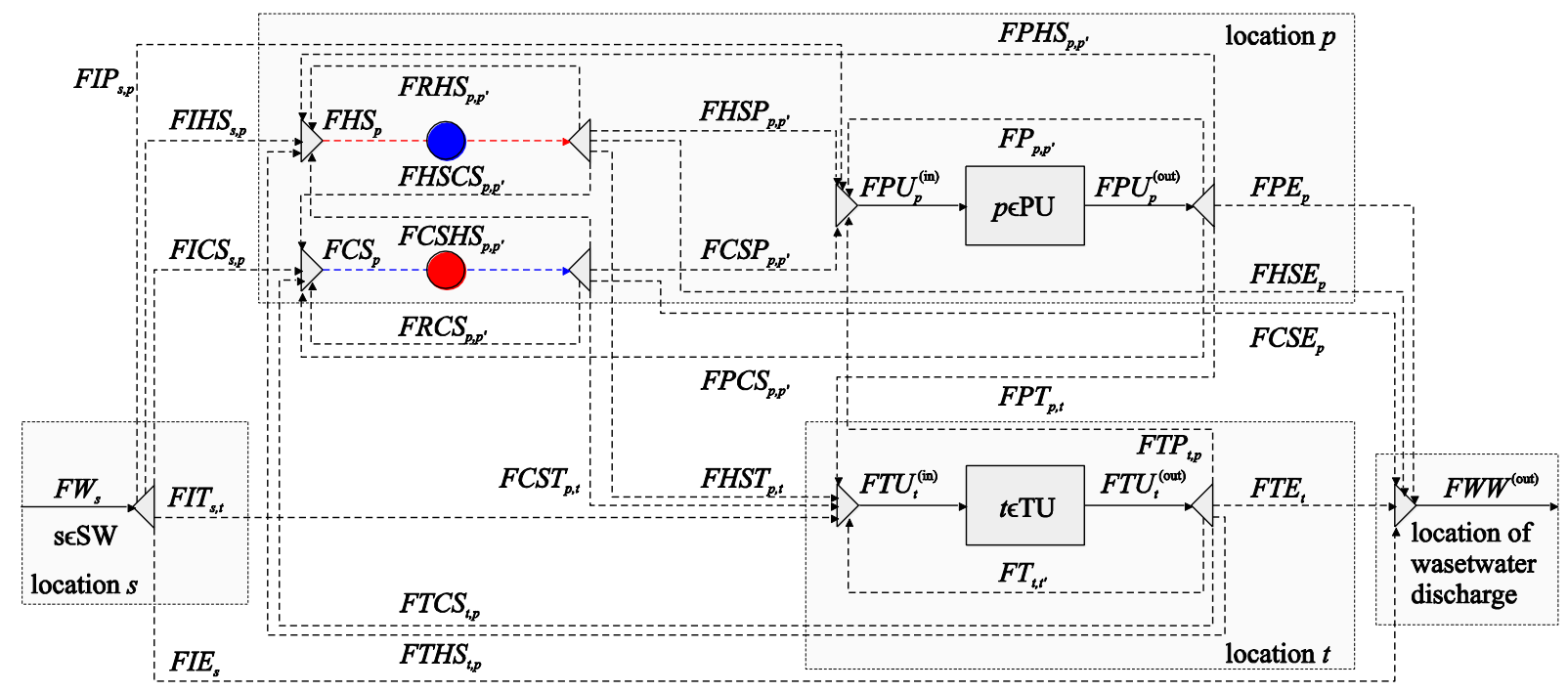

Fig. 2. A detailed superstructure representation of an individual network.

\section{MATHEMATICAL MODEL AND SOLUTION APROACH}

Fig. 3 shows the overall model consisting of three sub-models, namely, the water network model (M1), the simultaneous optimisation and heat integration model (M2) (Duran and Grossmann, 1986) and the heat exchanger network model (M3) (Yee and Grossmann, 1990). These models were combined within a two-step iterative solution strategy (Ibrić et al., 2016) consisting of initialisation and design steps (Fig. 3). A description of a two-step solution strategy, and corresponding initialisation and design step is provided below.

Step 1: A combined nonlinear programming (NLP) model (M1-M2) was solved with the objective of minimising operating costs of the network including freshwater, hot and cold utilities and wastewater treatment. The model becomes an MINLP when the selection of treatment units is required amongst the different treatment technologies. The connection between the two models (M1 and M2) is achieved by using connecting equations (Appendix A4). These equations are used for identifying streams within the water network model M1 that are hot/cold and assigning them to the corresponding hot/cold streams within model M2. Solving the NLP/MINLP model will provide initialisation for variables (e.g. flow rates, contaminants concentration) and lower and upper bounds on freshwater and utilities consumptions which will be used for the second step (see Appendix A5).

Step 2: A combined mixed integer nonlinear programming (MINLP) model (M1-M3) is solved simultaneously with the objective of minimising TAC of the network. Note that the MINLP model is not solved sequentially but rather simultaneously combining water networks model (M1) with the heat exchanger network model (M3) using the connecting equations (Appendix A4).

Steps 1 and 2 are solved within the iterative procedure in which the heat recovery approach temperature (HRAT) required for solving M1-M2 is changed within the each iteration providing different bound for 
water and utilities consumption and consequently different initialisation for the model M1-M3. A detailed explanation of the iterative procedure related to obtaining multiple locally optimal solutions can be found in our recent publication (Ibrić et al., 2016). Iterative procedure requires subsequent solution of multiple first NLPs/MINLPs and second MINLPs requiring additional time for obtaining the solution. However, a multiple solutions can be obtained and the best one can be chosen among the proposed solutions.

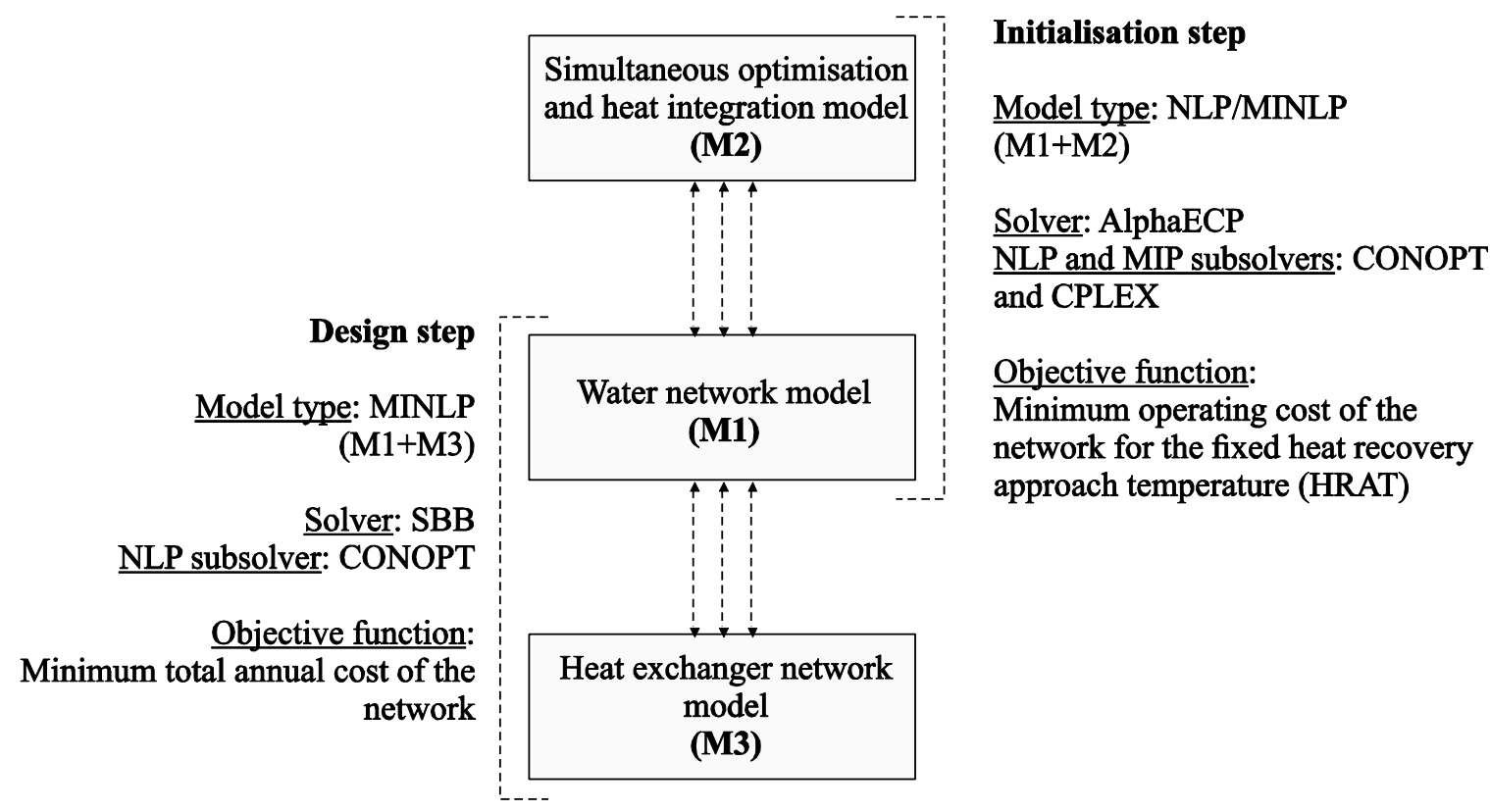

Fig. 3. Model components and solution approach (Ibrić et al., 2016b).

A detailed description of the water network model related to proposed superstructure is given in the following section (section 4.1) as well as the modified objective function that considers piping installation cost. A description of the models M2 and M3 is given within the Appendix A1 and A2. The important part of the model is the variables bounds. The bound can be obtained using known temperature levels, maximum inlet/outlet contaminants concentrations and maximum water flow rates within process water-using units. The reader is referred to recent paper (Ibrić et al., 2016) for the further details about deriving the generalized variables bounds.

The model was developed using General Algebraic Modelling System (GAMS) (Rosenthal, 2015). ALPHAECP solver is selected for the first step, with CONOPT and CPLEX as NLP and MIP subsolvers. To solve the MINLP model within the second step SBB solver was used with the assistance of CONOPT as root and sub-solver and SNOPT as solver for infeasible sequences. All the examples were solved on a laptop computer with $2.6 \mathrm{GHz}$ processor and $8 \mathrm{~GB}$ of RAM. 


\subsection{Water network model (M1)}

This section provides a description of the water network model (M1). The model M1 is based on the proposed superstructure shown in Fig. 2 and consists of mass and heat balance equations of each splitter, mixer, process unit and wastewater treatment unit. Parameters $Y P P\left(p, p^{\prime}\right), Y P T(p, t)$ and $Y T T\left(t, t^{\prime}\right)$ denote the existence of connections between the elements within the sets $p \in P U$ and $t \in T U$. Note that parameters are included if and only if parameter WINT $=0$ disabling direct water integration between different plants. The modelling of those parameters is described in details in section 4.1.9.

\subsubsection{Freshwater splitter mass balance}

The freshwater splitter mass balance is described by Eq. (1).

$$
F W_{s}=\sum_{p \in P U} F I P_{s, p}+\sum_{t \in T U} F I T_{s, t}+\sum_{p \in P U} F I H S_{s, p}+\sum_{p \in P U} F I C S_{s, p}+F I E_{s} \quad \forall s \in S F W
$$

\subsubsection{Hot streams cooling stages}

Within the proposed model (Ibrić et al., 2016) the user can define maximum number of hot streams as a set of cooling stages. However, in order to assign a location for the calculation of piping cost the number of hot and cold streams is directly related to the number of process water-using unit $p \in P U$. Eqs. (2)-(4) describe the mass and heat balance for the cooling stages mixers. The cooling stages splitter mass balance is given by Eq. (5).

$$
\begin{aligned}
& F H S_{p}=\sum_{s \in S F W} F I H S_{s, p}+\sum_{\substack{p p^{\prime} \in P U \\
Y P P\left(p^{p}\right)=1 \leftrightarrow W I N T=0}} F P H S_{p^{\prime}, p}+\sum_{\substack{t \in T U \\
Y P T(p, t)=1 \leftrightarrow W I N T=0}} F T H S_{t, p} \\
& +\sum_{\substack{p^{\prime} \in P U \\
p \neq p^{\prime} \\
Y P P\left(p^{\prime} p\right)=1 \leftrightarrow W I N T=0}} F R H S_{p^{\prime}, p}+\sum_{\substack{p^{\prime} \in P U \\
Y P P\left(p^{\prime} p\right)=1 \leftrightarrow W I N T=0}} F C S H S_{p^{\prime}, p} \quad \forall p \in P U
\end{aligned}
$$

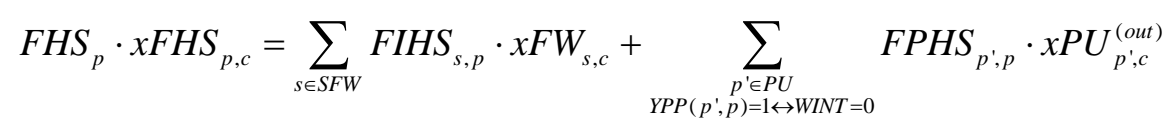

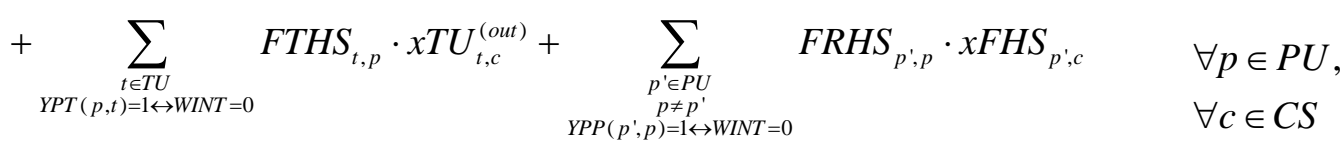

$$
\begin{aligned}
& +\sum_{\substack{p^{\prime} \in P U \\
Y P P\left(p^{\prime}, p\right)=1 \leftrightarrow W I N T=0}} F C S H S_{p^{\prime}, p} \cdot x F C S_{p^{\prime}, c} \\
& \begin{aligned}
F H S_{p} \cdot T H S_{p}^{(i n)}=\sum_{s \in S F W} F I H S_{s, p} \cdot T F W_{s}+\sum_{\substack{Y P P\left(p^{\prime}, p\right)=P U \\
p^{\prime} \in W I N T=0}} F P H S_{p^{\prime}, p} \cdot T P U_{p^{\prime}}^{(\text {out })} \\
+\sum_{\substack{t \in T U \\
Y P T(p, t)=1 \leftrightarrow W I N T=0}} F T H S_{t, p} \cdot T T U_{t}^{(\text {out })}+\sum_{\substack{p^{\prime} \in P U \\
p p^{\prime} \\
Y P P\left(p^{\prime}, p\right)=1 \leftrightarrow W I N T=0}} F R H S_{p^{\prime}, p} \cdot T H S_{p^{\prime}}^{(\text {out })} \quad \forall p \in P U \\
+\sum_{\substack{p^{\prime} \in P U \\
Y P P\left(p^{\prime}, p\right)=1 \leftrightarrow W I N T=0}} F C S H S_{p^{\prime}, p} \cdot T C S_{p^{\prime}}^{(\text {out })}
\end{aligned}
\end{aligned}
$$




$$
\begin{aligned}
& F H S_{p}=\sum_{\substack{p^{\prime} \in P U \\
Y P P\left(p, p^{\prime}\right)=1 \leftrightarrow W I N T=0}} F H S P_{p, p^{\prime}}+\sum_{\substack{t \in T U \\
Y P T(p, t)=1 \leftrightarrow W I N T=0}} F H S T_{p, t}+\sum_{\substack{p^{\prime} \in P U \\
p=p^{\prime} \\
Y P P\left(p, p p^{\prime}=1 \leftrightarrow W I N T=0\right.}} F R H S_{p, p^{\prime}} \\
& +\sum_{\substack{p^{\prime} \in P U \\
Y P P\left(p, p^{\prime}\right)=1 \leftrightarrow W I N T=0}} F H S C S_{p, p^{\prime}}+F H S E_{p} \\
& \forall p \in P U
\end{aligned}
$$

\subsubsection{Cold streams heating stages}

As described within the previous section, the similar modelling is used for heating stages with respect to the number of process water-using units $p \in P U$. Equations (6)-(8) describe the mass and heat balance for the cold streams heating stages mixers corresponding to each process unit $p \in P U$. The heating stages splitter mass balance is given by Eq. (9).

$$
\begin{aligned}
& F C S_{p}=\sum_{s \in S F W} F I C S_{s, p}+\sum_{\substack{p^{\prime} \in P U \\
Y P P\left(p^{\prime}, p\right)=1 \leftrightarrow W I N T=0}} F P C S_{p^{\prime}, p}+\sum_{\substack{t \in T U \\
Y P T(p, t)=1 \leftrightarrow W I N T=0}} F T C S_{t, p} \\
& +\sum_{\substack{p^{\prime} \in P U \\
p^{\prime} \neq p \\
Y P P\left(p^{\prime}, p\right)=1 \leftrightarrow W I N T=0}} F R C S_{p^{\prime}, p}+\sum_{\substack{p^{\prime} \in P U \\
Y P P\left(p^{\prime}, p\right)=1 \leftrightarrow W I N T=0}} F H S C S_{p^{\prime}, p} \quad \forall p \in P U \\
& F C S_{p} \cdot x F C S_{p, c}=\sum_{s \in S F W} F I C S_{s, p} \cdot x F W_{s, c}+\sum_{\substack{p \\
Y P P\left(p^{\prime}, p\right)=1 \leftrightarrow W I N T=0}} F P C S_{p^{\prime}, p} \cdot x P U_{p^{\prime}, c}^{(o u t)} \\
& +\sum_{\substack{t \in T U \\
Y P T(p, t)=1 \leftrightarrow W I N T=0}} F T C S_{t, p} \cdot x T U_{t, c}^{(\text {out })}+\sum_{\substack{p^{\prime} \in P U \\
p^{\prime \neq p} \\
Y P P\left(p^{\prime}, p=1 \leftrightarrow W I N T=0\right.}} F R C S_{p^{\prime}, p} \cdot x F C S_{p^{\prime}, c} \quad \begin{array}{l}
\forall p \in P U, \\
\forall c \in C S
\end{array} \\
& +\sum_{\substack{p^{\prime} \in P U \\
Y P P\left(p^{\prime}, p\right)=1 \leftrightarrow W I N T=0}} F_{H S C S_{p^{\prime}, p}} \cdot x F H S_{p^{\prime}, c} \\
& F C S_{p} \cdot T C S_{p}^{(i n)}=\sum_{s \in S F W} F I C S_{s, p} \cdot T F W_{s}+\sum_{\substack{p^{\prime} \in P U \\
Y P P\left(p^{\prime}, p\right)=1 \leftrightarrow W I N T=0}} F P C S_{p^{\prime}, p} \cdot T P U_{p^{\prime}}^{(\text {out })} \\
& +\sum_{\substack{t \in T U \\
Y P T(p, t)=1 \leftrightarrow W I N T=0}} F_{T C S_{t, p}} \cdot T T U_{t}^{(\text {out })}+\sum_{\substack{p^{\prime} \in P U \\
p \neq p \\
Y P P\left(p^{\prime}, p\right)=1 \leftrightarrow W I N T=0}} F R C S_{p^{\prime}, p} \cdot T C S_{p^{\prime}}^{(\text {out })} \quad \forall p \in P U \\
& +\sum_{\substack{p^{\prime} \in P U \\
Y P P\left(p^{\prime}, p\right)=1 \leftrightarrow W I N T=0}} F H S C S_{p^{\prime}, p} \cdot T H S_{p^{\prime}}^{(\text {out })}
\end{aligned}
$$

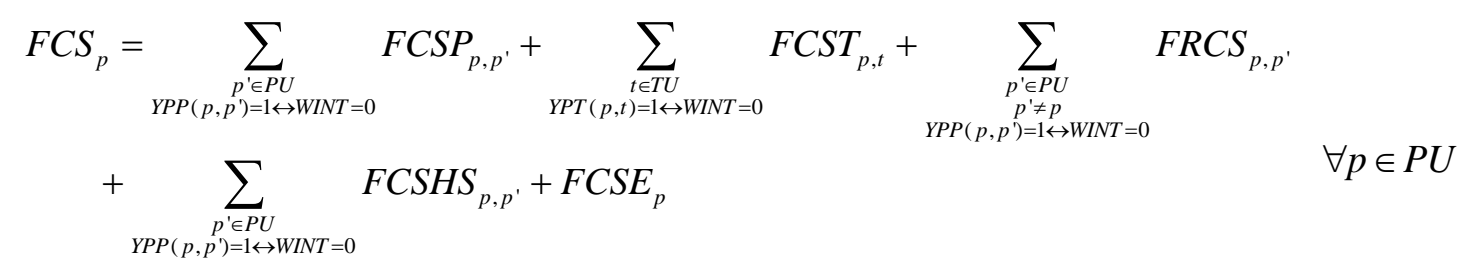




\subsubsection{Process units}

Process unit $p \in P U$ mixer mass and heat balance is given by Eqs. (10)-(12). In the process unit $p$, the fixed amount of contaminant $\left(M L_{p, c}\right)$ is transferred to the water stream. Since the mass load $\left(M L_{p, c}\right)$ of the contaminants is very small the water flow rate through the process unit $p$ is assumed unchanged. The mass balance for the process unit $p$ is given by Eqs. (13) -(14) And for the process unit $p$ splitter by Eq. (15).

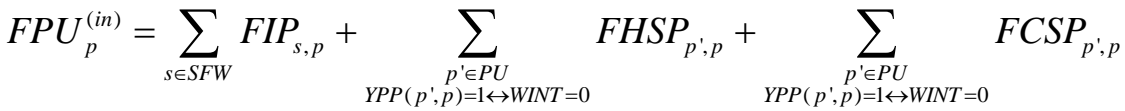

$$
\begin{aligned}
& +\sum_{\substack{p^{\prime} \in P U \\
p \neq p^{\prime} \\
Y P P\left(p^{\prime}, p\right)=1 \leftrightarrow W I N T=0}} F P_{p^{\prime}, p}+\sum_{\substack{t \in T U \\
Y P T(p, t)=1 \leftrightarrow W I N T=0}} F T P_{t, p} \\
& F P U_{p}^{(i n)} \cdot x P U_{p, c}^{(i n)}=\sum_{s \in S F W} F I P_{s, p} \cdot x F W_{s, c}+\sum_{\substack{p^{\prime} \in P U \\
Y P P\left(p^{\prime}, p\right)=1 \leftrightarrow W I N T=0}} F H S P_{p^{\prime}, p} \cdot x F H S_{p^{\prime}, c}+ \\
& +\sum_{\substack{p^{\prime} \in P U \\
Y P P\left(p^{\prime}, p\right)=1 \leftrightarrow W I N T=0}} F C S P_{p^{\prime}, p} \cdot x F C S_{p^{\prime}, c}+\sum_{\substack{p^{\prime} \in P U \\
p \neq p^{\prime} \\
Y P P\left(p^{\prime}, p\right)=1 \leftrightarrow W I N T=0}} F P_{p^{\prime}, p} \cdot x P U_{p^{\prime}, c}^{(o u t)}+\quad \begin{array}{l}
\forall p \in P U, \\
\forall c \in C S
\end{array} \\
& +\sum_{\substack{t \in T U \\
Y P T(p, t)=1 \leftrightarrow W I N T=0}} F T P_{t, p} \cdot x T U_{t, c}^{(o u t)} \\
& \operatorname{YPP}\left(p^{\prime}, p\right)=1 \leftrightarrow W I N T=0 \\
& \forall p \in P U \\
& +\sum_{\substack{p^{\prime} \in P U \\
Y P P\left(p^{\prime}, p\right)=1 \leftrightarrow W I N T=0}} F C S P_{p^{\prime}, p} \cdot T C S_{p^{\prime}}^{(\text {out })}+\sum_{\substack{p^{\prime} \in P U \\
p \neq p^{\prime} \\
Y P P\left(p^{\prime}, p\right)=1 \leftrightarrow W I N T=0}} F P_{p^{\prime}, p} \cdot T P U_{p^{\prime}}^{(\text {out })} \quad \forall p \in P U \\
& F P U_{p}^{(i n)} \cdot T P U_{p}^{(i n)}=\sum_{s \in S F W} F I P_{s, p} \cdot T F W_{s}+\sum_{\substack{p^{\prime} \in P U \\
Y P P\left(p^{\prime}, p\right)=1 \leftrightarrow W I N T=0}} F H S P_{p^{\prime}, p} \cdot T H S_{p^{\prime}}^{(\text {out })} \\
& +\sum_{\substack{p^{\prime} \in P U \\
Y P P\left(p^{\prime}, p\right)=\uparrow \rightarrow\left(\leftrightarrow, N T=0 \\
p \neq p^{\prime}\right.}} F P_{p^{\prime}, p} \cdot T P U_{p^{\prime}}^{(\text {out })}+\sum_{\substack{t \in T U \\
Y P T(p, t)=1 \leftrightarrow W I N T=0}} F T P_{t, p} \cdot T T U_{t}^{(\text {out })} \\
& F P U_{p}^{(i n)}=F P U_{p}^{(o u t)} \\
& \forall p \in P U \\
& F P U_{p}^{(i n)} \cdot x P U_{p, c}^{(i n)}+M L_{p, c}=F P U_{p}^{(o u t)} \cdot x P U_{p, c}^{(o u t)} \\
& \forall p \in P U \\
& F P U_{p}^{(\text {out })}=\sum_{\substack{p^{\prime} \in P U \\
p \neq p^{\prime} \\
Y P P\left(p, p^{\prime}\right)=1 \leftrightarrow W I N T=0}} F P_{p, p^{\prime}}+\sum_{\substack{t \in T U \\
Y P T(p, t)=1 \leftrightarrow W I N T=0}} F P T_{p, t} \quad \forall p \in P U \\
& +\sum_{\substack{p \in P U \\
Y P P\left(p, p^{\prime}\right)=1 \leftrightarrow W I N T=0}} F P H S_{p, p^{\prime}}+\sum_{\substack{p \in P U \\
Y P P\left(p, p^{\prime}\right)=1 \leftrightarrow W I N T=0}} F P C S_{p, p^{\prime}}+F P E_{p}
\end{aligned}
$$




\subsubsection{Treatment units}

The mass and heat balance constraints of the mixer of the treatment unit $t \in T U$ are given by equations (Eqs. (16)-(18)).

$$
\begin{aligned}
& F T U_{t}^{(i n)}=\sum_{s \in S F W} F I T_{s, t}+\sum_{\substack{p \in P U \\
Y P T(p, t)=1 \leftrightarrow W I N T=0}} F P T_{p, t}+\sum_{\substack{t^{\prime} \in T U \\
\neq t t^{\prime} \\
Y I T\left(t^{\prime}, t\right)=1 \leftrightarrow W I N T=0}} F T_{t^{\prime}, t} \\
& +\sum_{\substack{p \in P U \\
Y P T(p, t)=1 \leftrightarrow W I N T=0}} F H S T_{p, t}+\sum_{\substack{p \in P U \\
Y P T(p, t)=1 \leftrightarrow W I N T=0}} F C S T_{p, t} \\
& F T U_{t}^{(i n)} \cdot x T U_{t, c}^{(i n)}=\sum_{s \in S F W} F I T_{s, t} \cdot x F W_{s, c}+\sum_{\substack{p \in P U \\
Y P T(p, t)=1 \leftrightarrow W I N T=0}} F P T_{p, t} \cdot x P U_{p, c}^{(o u t)}
\end{aligned}
$$

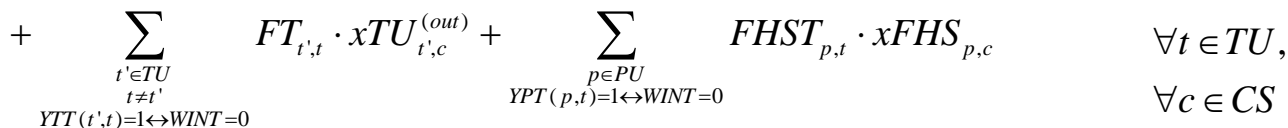

$$
\begin{aligned}
& +\sum_{\substack{p \in P U \\
Y P T(p, t)=1 \leftrightarrow W I N T=0}}^{Y T T\left(t^{\prime}, t\right)=1 \leftrightarrow W I N T=0}{ }_{C S T_{p, t}} \cdot x F C S_{c s, c} \\
& F T U_{t}^{(i n)} \cdot T T U_{t}^{(i n)}=\sum_{s \in S F W} F I T_{s, t} \cdot T F W_{s}+\sum_{\substack{p \in P U \\
Y P T(p, t)=1 \leftrightarrow W I N T=0}} F P T_{p, t} \cdot T P U_{p}^{(o u t)} \\
& +\sum_{\substack{t^{\prime} \in T U \\
t \neq t^{\prime} \\
Y T T\left(t^{\prime}, t\right)=1 \leftrightarrow W I N T=0}} F T_{t^{\prime}, t} \cdot T T U_{t^{\prime}}^{(\text {out })}+\sum_{\substack{p \in P U \\
Y P T(p, t)=1 \leftrightarrow W I N T=0}} F H S T_{p, t} \cdot T H S_{p, c}^{(\text {out })} \quad \forall t \in T U \\
& +\sum_{\substack{p \in P U \\
Y P T(p, t)=1 \leftrightarrow W I N T=0}} F C S T_{p, t} \cdot T C S_{p}^{(o u t)} \\
& \forall t \in T U
\end{aligned}
$$

The fixed removal ratio $\left(R R_{t, c}\right)$ of the contaminant $c$ is assumed within the treatment unit. Also, it is assumed that the mass flow rate of wastewater through the treatment unit is constant because the water flow rate is much higher than the amount of removed contaminants. The mass balance for the treatment unit $t$ is given by Eqs. (19)-(20). Eq. (21) defines the maximum number of treatment units selected ( $N_{S T U}$ ) amongst several available treatment units. Water flow rate in the treatment unit $t$ is constrained by Eq. (22). The water mass balance for the treatment unit $t \in T U$ splitter is given by Eq. (23).

$$
\begin{array}{ll}
T T U_{t}^{(i n)}=T T U_{t}^{(\text {out })} & \forall t \in T U \\
F T U_{t}^{(i n)} \cdot x T U_{t, c}^{(i n)} \cdot\left(1-R R_{t, c}\right)=F T U_{t}^{(\text {out })} \cdot x T U_{t, c}^{(\text {out })} & \forall t \in T U, \\
\sum_{t \in T U} y T U_{t} \leq N_{S T U} & \forall c \in C S \\
F T U_{t}^{(i n)} \leq F T U_{t}^{(i n), U} \cdot y T U_{t} & \\
\end{array}
$$




$$
\begin{aligned}
& F T U_{t}^{(\text {out })}=\sum_{\substack{p \in P U \\
Y P T(p, t)=1 \leftrightarrow W I N T=0}} F T P_{t, p}+\sum_{\substack{t^{\prime} \in T U \\
t \neq t^{\prime} \\
Y T T\left(t, t^{\prime}\right)=1 \leftrightarrow W N T=0}} F T_{t, t^{\prime}} \\
& +\sum_{\substack{p \in P U \\
Y P T(p, t)=1 \leftrightarrow W I N T=0}} F T H S_{t, p}+\sum_{\substack{p \in P U \\
Y P T(p, t)=1 \leftrightarrow W I N T=0}} F T C S_{t, p}+F T E_{t}
\end{aligned}
$$

\subsubsection{Final wastewater mixer}

The overall water mass balance and heat balance of the wastewater mixer is given by Eqs (24)-(26).

$$
\begin{aligned}
& F W W^{(\text {out })}=\sum_{s \in S F W} F I E_{s}+\sum_{p \in P U} F P E_{p}+\sum_{t \in T U} F T E_{t} \\
& +\sum_{p \in P U} F H S E_{p}+\sum_{p \in P U} F C S E_{p} \\
& F W W^{(\text {out })} \cdot x W W_{c}^{(\text {out })}=\sum_{s \in S F W} F I E_{s} \cdot x F W_{s, c}+\sum_{p \in P U} F P E_{p} \cdot x P U_{p, c}^{(\text {out })} \\
& +\sum_{t \in T U} F T E_{t} \cdot x T U_{t, c}^{(o u t)}+\sum_{p \in P U} F H S E_{p} \cdot x F H S_{p, c}+\sum_{p \in P U} F C S E_{p} \cdot x F C S_{p, c} \\
& F W W^{(\text {out })} \cdot T W W^{(\text {out })}=\sum_{s \in S F W} F I E_{s} \cdot T F W_{s}+\sum_{p \in P U} F P E_{p} \cdot T P U_{p}^{(\text {out })} \\
& +\sum_{t \in T U} F T E_{t} \cdot T T U_{t}^{(\text {out })}+\sum_{p \in P U} F H S E_{p} \cdot T H S_{p}^{(\text {out })}+\sum_{p \in P U} F C S E_{p} \cdot T C S_{p}^{(\text {out })}
\end{aligned}
$$

\subsubsection{Global mass balance equations}

Global overall mass balance and mass balances for each contaminant $c \in S C$ (Karuppiah and Grossmann, 2006) is given by Eqs. (27) and (28).

$$
\begin{aligned}
& \sum_{s \in S F W} F W_{s}=F W W^{(o u t)} \\
& \sum_{s \in S F W} F W_{s} \cdot x F W_{s, c}+\sum_{p \in P U} M L_{p, c}-\sum_{t \in T U} F T U_{t}^{(i n)} \cdot x T U_{t, c}^{(i n)} \cdot R R_{t, c} \\
& =F W W^{(o u t)} \cdot x W W_{c}^{(o u t)}
\end{aligned}
$$

\subsubsection{Objective function}

The objective function of the combined model M1-M2 is defined as the minimisation of operating cost of the network (Eq. (29)) including freshwater, utilities and wastewater treatment. The objective function of the combined model M1-M3 is given as minimisation of TAC of the overall network (Eq. (30)) including operating cost of the network (freshwater, utilities and wastewater treatment cost) and investment cost (HEN, treatment units and piping). The annualised piping installation cost $(\$ /(\mathrm{m} \cdot \mathrm{y}))$ is modelled as a function of mass $(\mathrm{kg} / \mathrm{s})$ flow rate. The given function $A_{\text {piping }} \cdot(\text { flowrate })^{B_{\text {piping }}}$ relates to the 
optimum economic pipe diameter that also accounts for minimum fluid pumping cost. Section 4.1.10 presents a detailed procedure for obtaining economic pipe diameter and pipe investment cost.

$$
\begin{aligned}
& \operatorname{minZ}_{M 1-M 2}=H \cdot \sum_{s \in S F W} F W_{s} \cdot C F W_{s}+q c u \cdot C_{C U}+q h u \cdot C_{H U}+H \cdot \sum_{t \in T U} F T U_{t}^{(i n)} \cdot O C_{t} \\
& \min Z_{M 1-M 3}=H \cdot \sum_{s \in S F W} F W_{s} \cdot C F W_{s}+\sum_{i \in H P} q c_{i} \cdot C_{C U}+\sum_{j \in C P} q h_{j} \cdot C_{H U}+H \cdot \sum_{t \in T U} F T U_{t}^{(i n)} \cdot O C_{t}+ \\
& A F \cdot \sum_{t \in T U} I C_{t} \cdot\left(F T U_{t}^{(i n)}\right)^{\alpha_{t}}+C F \cdot\left(\sum_{i \in H P} \sum_{j \in C P} \sum_{k \in S T} z_{i, j, k}+\sum_{i \in H P} z c u_{i}+\sum_{j \in H P} z h u_{j}\right)+ \\
& \sum_{i \in H P} \sum_{j \in C P} \sum_{k \in S T} C_{i, j} \cdot A_{i, j, k}^{B}+\sum_{i \in H P} C_{i, C U} \cdot A_{i, C U}^{B}+\sum_{j \in C P} C_{j, H U} \cdot A_{j, H U}^{B}+ \\
& \sum_{s \in S F W} \sum_{p \in P U}\left(\begin{array}{l}
\left(A_{\text {piping }} \cdot\left(F I P_{s, p}\right)^{B_{\text {piping }}}+\left(A_{\text {piping }} \cdot\left(F I H S_{s, p}\right)^{B_{p i p i n g}}+\right.\right. \\
\left(A_{\text {piping }} \cdot\left(F I C S_{s, p}\right)^{B_{\text {piping }}}\right.
\end{array}\right) \cdot L S P_{s, p}+ \\
& \sum_{s \in S F W} \sum_{t \in T U}\left(\left(A_{\text {piping }} \cdot\left(F I T_{s, t}\right)^{B_{\text {piping }}}\right) \cdot L S T_{s, t}+\sum_{s \in S F W}\left(\left(A_{\text {piping }} \cdot\left(F I E_{s}\right)^{B_{\text {piping }}}\right) \cdot L S E_{s}+\right.\right. \\
& \sum_{p \in P U}\left(\begin{array}{l}
\left(A_{\text {piping }} \cdot\left(F P E_{p}\right)^{B_{\text {piping }}}+\left(A_{\text {piping }} \cdot\left(F H S E_{p}\right)^{B_{\text {piping }}}+\right.\right. \\
\left(A_{\text {piping }} \cdot\left(F C S E_{p}\right)^{B_{\text {piping }}}\right.
\end{array}\right) \cdot L P E_{p}+ \\
& \sum_{p \in P U}\left(\left(A_{\text {piping }} \cdot\left(F H S_{p}\right)^{B_{p i p i n g}}+\left(A_{\text {piping }} \cdot\left(F C S_{p}\right)^{B_{p i p i n g}}\right)+\right.\right. \\
& \sum_{p \in P U} \sum_{p^{\prime} \in P U}\left(\begin{array}{l}
\left(A_{\text {piping }} \cdot\left(F P H S_{p, p^{\prime}}\right)^{B_{p i p i n g}}+\left(A_{p i p i n g} \cdot\left(F P C S_{p, p^{\prime}}\right)^{B_{p i p i n g}}+\right.\right. \\
\left(A_{p i p i n g} \cdot\left(F R H S_{p, p^{\prime}}\right)^{B_{p i p i n g}}+\left(A_{p i p i n g} \cdot\left(F R C S_{p, p^{\prime}}\right)^{B_{p i p i n g}}+\right.\right. \\
\left(A_{p i p i n g} \cdot\left(F H S P_{p, p^{\prime}}\right)^{B_{p i p i n g}}+\left(A_{p i p i n g} \cdot\left(F C S P_{p, p^{\prime}}\right)^{B_{p i p i n g}}+\right.\right. \\
\left(A_{p i p i n g} \cdot\left(F P_{p, p^{\prime}}\right)^{B_{p i p i n g}}+\left(A_{p i p i n g} \cdot\left(F H S C S_{p, p^{\prime}}\right)^{B_{p i p i n g}}+\right.\right. \\
\left(A_{\text {piping }} \cdot\left(F C S H S_{p, p^{\prime}}\right)^{B_{p p i n i n g}}\right.
\end{array}\right) \cdot L S P_{p, p^{\prime}}+ \\
& \sum_{t \in P U}\left(\left(A_{\text {piping }} \cdot\left(F T E_{t}\right)^{B_{p \text { ping }}}\right) \cdot L T E_{t}+\sum_{t \in T U} \sum_{t^{\prime} \in T U}\left(\left(A_{\text {piping }} \cdot\left(F T_{t, t^{\prime}}\right)^{B_{\text {pining }}}\right) \cdot L T_{t, t^{\prime}}+\right.\right. \\
& \sum_{p \in P U} \sum_{t \in T U}\left(\begin{array}{l}
\left(A_{\text {piping }} \cdot\left(F T H S_{t, p}\right)^{B_{\text {piping }}}+\left(A_{\text {piping }} \cdot\left(F T C S_{t, p}\right)^{B_{p i p i n g}}+\right.\right. \\
\left(A_{\text {piping }} \cdot\left(F T P_{t, p}\right)^{B_{\text {piping }}}+\left(A_{\text {piping }} \cdot\left(F H S T_{p, t}\right)^{B_{p i p i n g}}+\right.\right. \\
\left(A_{\text {piping }} \cdot\left(F C S T_{p, t}\right)^{B_{\text {piping }}}+\left(A_{\text {piping }} \cdot\left(F P T_{p, t}\right)^{B_{p i p i n g}}\right.\right.
\end{array}\right) \cdot L P T_{p, t}
\end{aligned}
$$

\subsubsection{Modelling of interplant connections}

The identification of the process water-using units, wastewater treatment units and their mutual connections within and between the plants is modelled by introducing binary parameters instead of using an additional set of plants or binary variables. Consequently, this does not increase the complexity of the model when compared to the synthesis of stand-alone networks.

An auxiliary set containing number of plants is introduced $(p l \in P L T)$ for defining the binary parameters for the connections between process water-using units $Y P P\left(p, p^{\prime}\right)$, wastewater treatment units $Y T T\left(t, t^{\prime}\right)$, inter connections between process water-using units and wastewater treatment units 
$Y P T(p, t)$ and the heat exchange matches $H X(i, j)$. In addition, parameters $N P U_{p l}$ and $N T U_{p l}$ are introduced having values corresponding to the number of the last element of the sets $p \in P U$ and $t \in T U$ within each plant $p l \in P L T$ (Eq.(31)). Thus, the values for binary parameters can be assigned using generalized formulation for any number of plants, units etc.

$$
\begin{aligned}
& N P U_{p l}=|P U|_{p l}+|P U|_{p l-1}+\mathrm{K}+|P U|_{1}, p l>1 \\
& N T U_{p l}=|T U|_{p l}+|T U|_{p l-1}+\mathrm{K}+|T U|_{1}, p l>1
\end{aligned}
$$

If the value of binary parameter is equal to 1 the connections between units exists and otherwise it is disabled. Equation (32) describes the assignment of value 1 to the binary parameter $Y P P\left(p, p^{\prime}\right)$ for the connections between the process water-using units. If we define e.g. the number of plants $|P L T|=2$, a total number of process water-using units $|P U|=4$, the value of the parameters $N P U_{p l}$ would be $N P U_{1}=2$ and $N P U_{2}=4$ for the case when the first two units are assigned to plant 1 and other within plant 2. The mathematical formulation given by Eq. (32) gives the parameter values as shown in Table 1 .

$$
\begin{aligned}
& Y P P\left(p, p^{\prime}\right)=1, \quad p \leq N P U_{p l} \wedge p^{\prime} \leq N P U_{p l}, p l=1 \\
& Y P P\left(p, p^{\prime}\right)=1, \quad p, p^{\prime}>N P U_{p l-1} \wedge p, p^{\prime} \leq N P U_{p l}, p l>1 \wedge p l<|P L T| \\
& Y P P\left(p, p^{\prime}\right)=1, \quad p, p^{\prime}>N P U_{p l-1}, p l=|P L T|
\end{aligned}
$$

Note that connections for local recycling of water can be included if $p=p^{\prime}$. However, additional constraints within the model were imposed in order to restrict those connections $\left(p \neq p^{\prime}\right)$. Fig. 4 shows the existing network connections when the direct water integration between plants is a) enabled and b) disabled i.e. for connection having parameter values $\operatorname{YPP}\left(p, p^{\prime}\right)=0$. Note that when the direct water integration between plants is enabled as shown in Fig. 4a, it can be viewed as a single plant problem from the water integration point of view. When the direct water integration between plants is disabled, it is an interplant plant problem without direct water integration opportunities.

Table 1 Parameter $\operatorname{YPP}\left(p, p^{\prime}\right)$ values for the formulation given by Eq. (32).

\begin{tabular}{lllll}
\hline Process unit & $\mathrm{PU}_{1}$ & $\mathrm{PU}_{2}$ & $\mathrm{PU}_{3}$ & $\mathrm{PU}_{4}$ \\
\hline $\mathrm{PU}_{1}$ & 1 & 1 & 0 & 0 \\
$\mathrm{PU}_{2}$ & 1 & 1 & 0 & 0 \\
$\mathrm{PU}_{3}$ & 0 & 0 & 1 & 1 \\
$\mathrm{PU}_{4}$ & 0 & 0 & 1 & 1 \\
\hline
\end{tabular}




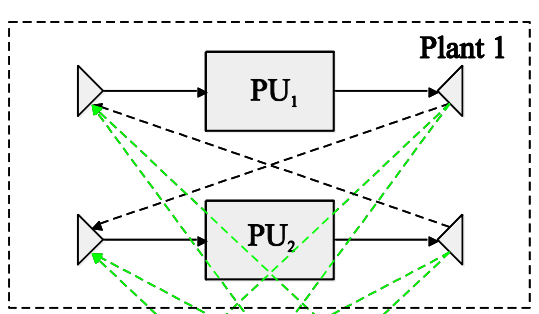

a)

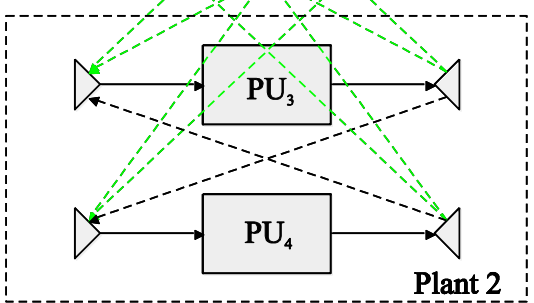

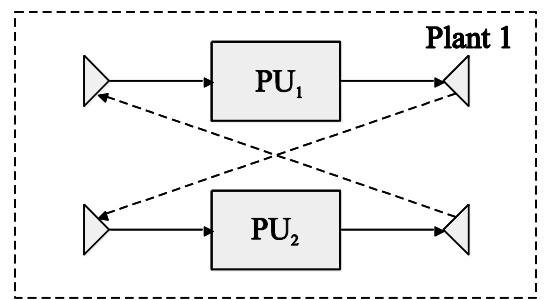

b)

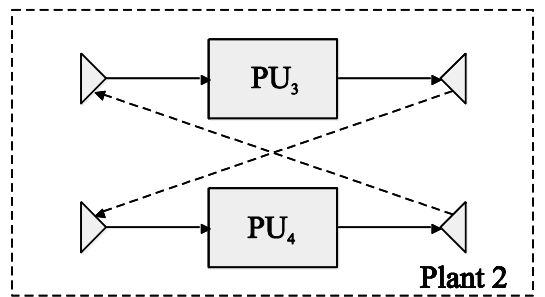

Fig. 4. Direct water integration between plants: a) enabled b) disabled.

Equations (33) and (34) describe the mathematical formulation for defining the parameters $Y T T\left(t, t^{\prime}\right)$ and $Y P T(p, t)$.

$$
\begin{array}{ll}
Y T T\left(t, t^{\prime}\right)=1, & t \leq N T U_{p l} \wedge t^{\prime} \leq N T U_{p l}, p l=1 \\
Y T T\left(t, t^{\prime}\right)=1, & t, t^{\prime}>N T U_{p l-1} \wedge t, t^{\prime} \leq N T U_{p l}, p l>1 \wedge p l<|P L T| \\
Y T T\left(t, t^{\prime}\right)=1, & t, t^{\prime}>N T U_{p l-1}, p l=|P L T| \\
Y P T(p, t)=1, & p \leq N P U_{p l} \wedge t \leq N T U_{p l}, p l=1 \\
Y P T(p, t)=1, & p>N P U_{p l-1} \wedge t>N T U_{p l-1} \wedge p \leq N T U_{p l} \wedge t \leq N T U_{p l}, p l>1 \wedge p l<|P L T| \\
Y P T(p, t)=1, & p>N P U_{p l-1} \wedge t>N T U_{p l-1}, p l=|P L T|
\end{array}
$$

In addition to the water integration options, Fig. 5 shows the heat integration options within the proposed superstructure. Heat integration options include non-isothermal mixing of water streams within and between heating and cooling stages as well as heat exchanges through heat exchangers. The mathematical formulation of the parameter $H X(i, j)$ defining the existence of indirect heat exchange matches is given as follows:

$$
\begin{array}{ll}
H X(i, j)=1, & i=p \leq N P U_{p l} \wedge j=p \leq N P U_{p l}, p l=1 \\
H X(i, j)=1, & i=j=p>N P U_{p l-1} \wedge i=j=p \leq N P U_{p l-1}, p l>1 \wedge p l<|P L T| \\
H X(i, j)=1, & i=j=p>N P U_{p l-1}, p l=|P L T|
\end{array}
$$




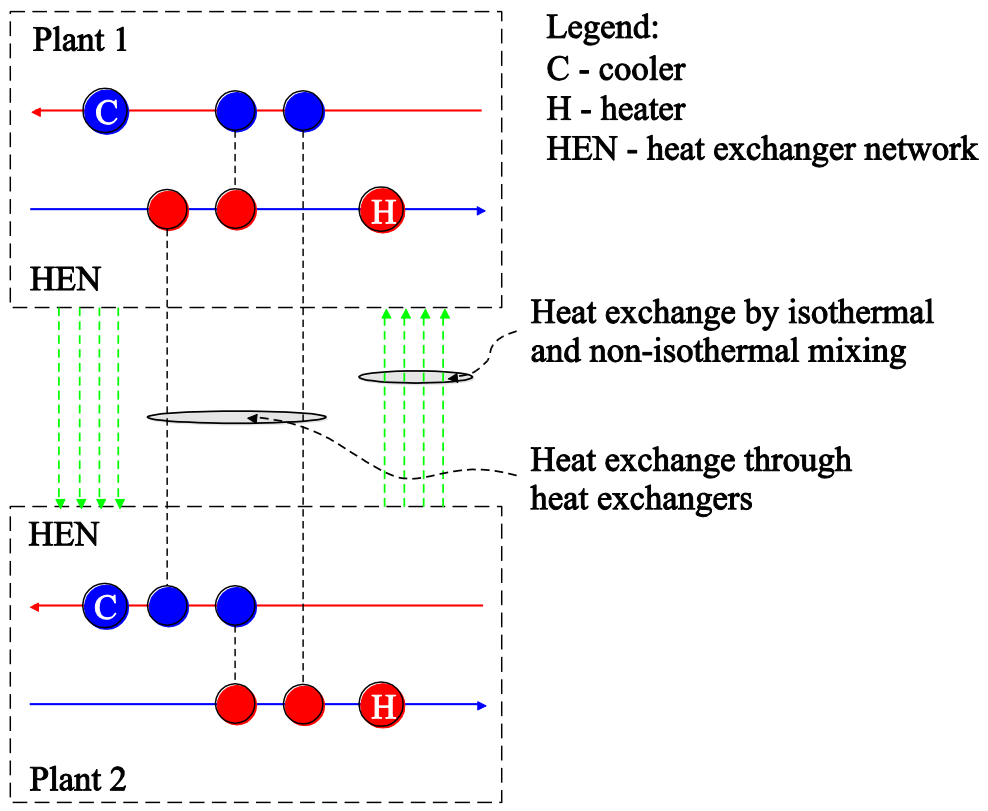

Fig. 5. Heat integration options within and between plants.

Based on the assigned values for the parameters defining connections between superstructure elements, different water and heat integration options can be explored. In addition, the parameters HINT and WINT are introduced. If HINT is set to 1 heat exchange through heat exchangers between separate plants are enabled and otherwise disabled. Please note that although the heat integration between hot and cold streams is enabled by the proposed model it is not considered in the studied examples. Heat integration of streams at the distant locations would in most case require additional investment in piping (Amidpour and Polley, 1997). We assume that only heat integration of streams within the same plant is possible. Direct water integration options between separate plants are enabled with parameter WINT having value 1 and otherwise disabled. The modelling of such options within the GAMS is easily manageable by using the dollar operator (Rosenthal, 2015). Note that HINT refers only to heat integration of hot and cold streams exchanging heat through heat exchangers.

\subsubsection{Economic pipe diameter and piping cost derivation}

The capital cost of the pipe run increases with the increase in the piping diameter whilst the electricity consumption to pump the fluid decreases. The most economic piping diameter is the one with the minimal total annual cost (Sinnott et al., 2005). Piping installation cost (\$/m) in the objective function given by Eq.(30) is considered as a function of the mass flow rate $A_{\text {piping }} \cdot(\text { flow rate) })^{B_{\text {piping }}}$. It is derived following the procedure presented by Sinnott et al. (2005).

The investment cost of piping is given by Eq. (36). The parameters $B$ and $n$ are related to investment cost including valves, fitting and installation cost. They depend on pipe material and pipe schedule. The internal piping diameter $(\mathrm{m})$ is presented by $d$. Pipe investment given by Eq. (36) is annualised $(\$ /(\mathrm{m} \cdot \mathrm{y})$ by using annualisation factor $A F$. The parameter $b$ accounts for the pipe maintenance in percentage/100. 
Values of the piping cost were taken from (Sinnott et al., 2005) for the carbon steel pipes. Annualisation factor is assumed to be $10 \%$ and maintenance typical value is $5 \%$.

$$
C_{\text {pipe }}^{(i n v)}=B \cdot d^{n} \cdot(A F+b)=221.5 \cdot d^{0.55}
$$

The operating cost of pipe run is related to water pumping cost and is given by. Eq. (37) assuming water density $1000 \mathrm{~kg} / \mathrm{m}^{3}$, plant operating hours $8000 \mathrm{~h} / \mathrm{y}$, electricity cost $0.067 \$ /(\mathrm{kW} \mathrm{h})$ and pump efficiency 0.6 .

$$
C_{\text {pipe }}^{(O P E R)}=\frac{\Delta p}{1000} \cdot \frac{F}{\rho} \cdot \frac{H \cdot C_{e l}}{\eta_{\text {pump }}}=\Delta p \cdot F \cdot C_{1}=\Delta p \cdot F \cdot C_{1}=\Delta p \cdot F \cdot 8.933 \cdot 10^{-4}
$$

In order to reduce the complexity the model an approximation of the pressure drop as a nonlinear function of the piping diameter $(\mathrm{m})$ and fluid mass flow rate $(\mathrm{kg} / \mathrm{s})$ was made as given by Eq. (38).

$$
\Delta p^{\text {model }}=C_{2} \cdot F^{C_{3}} \cdot d^{C_{4}}
$$

The values of the coefficients $C_{2}, C_{3}$ and $C_{4}$ were optimised by performing nonlinear regression minimising sum of squared error given by Eq. (39). The error is defined as a deviation of the estimated value of pressure drop from the value of pressure drop calculated by using Darcy-Weisbach equation.

$$
\min Z=\sum_{i=m}^{120}\left(\Delta p_{m}^{\text {model }}-\Delta p_{m}\right)^{2}
$$

The nonlinear regression was performed for a set of points $(m \in M)$ for which the values of pressure drop $\left(\Delta p_{m}\right)$ can be calculated for each point $m \in M$ by solving equations (40)-(43). The values for the fluid velocity are given within the interval $0.5-4 \mathrm{~m} / \mathrm{s}$ and pipe diameter range 0.0125-0.25 $\mathrm{m}$ assuming, dynamic viscosity $1 \cdot 10^{-3} \mathrm{~Pa} \cdot \mathrm{s}$ and carbon steel pipe absolute roughness $0.45 \cdot 10^{-3} \mathrm{~m}$. The pressure drop range for the defined constraints is 8-19040 Pa per m of pipe.

The pressure drop for the fluid flow in pipes can be described using the Darcy-Weisbach equation (Eq. (40)):

$$
\Delta p_{m}=\lambda_{m} \cdot \frac{L}{d_{m}} \cdot \frac{\rho \cdot v_{m}^{2}}{2} \quad m \in M
$$

Generally, friction factor depends on Reynolds number (Eq. (41)) and relative roughness $e / d$ of the pipe as given by Eq. (42).

$$
\begin{array}{ll}
\operatorname{Re}_{m}=\frac{d_{m} \cdot v_{m} \cdot \rho}{\mu} & m \in M \\
\frac{1}{\sqrt{\lambda_{m}}}=-2 \cdot \log \left(\frac{2.51}{\operatorname{Re}_{m} \cdot \sqrt{\lambda_{m}}}+\frac{k}{3.71 \cdot d_{m}}\right), \operatorname{Re}_{m} \cdot \frac{e}{d_{m}}>65 & m \in M
\end{array}
$$




$$
\lambda_{m}=1.8 \cdot \log \left(\frac{\operatorname{Re}_{m}}{7}\right)^{-2}, \operatorname{Re}_{m} \cdot \frac{e}{d_{m}} \leq 65 \quad m \in M
$$

The fluid velocity for a steady state flow is given by Eq. (43)

$$
v_{m}=\frac{4 \cdot F_{m}}{\rho \cdot d_{m}^{2} \cdot \pi} \quad \forall m \in M
$$

The optimised value of the parameters were $C_{2}=1.4768 \cdot 10^{-5}, C_{3}=1.916$ and $C_{4}=-5.097$ with objective value $Z=42376$. The objective of finding economic pipe diameter is minimizing TAC given by Eq. (44). Substituting pressure drop Eq. (38), Eq. (44) becomes Eq. (45).

$$
\begin{aligned}
C_{\text {pipe }}^{(T A C)}= & C_{\text {pipe }}^{(I N V)}+C_{\text {pipe }}^{(\text {OPER })}=221.5 \cdot d^{0.55}+\Delta p \cdot F \cdot 8.933 \cdot 10^{-4} \\
C_{p i p e}^{(T A C)} & =221.5 \cdot d^{0.55}+C_{2} \cdot F^{C_{3}} \cdot d^{C_{4}} \cdot F \cdot 8.933 \cdot 10^{-4} \\
& =221.5 \cdot d^{0.55}+C_{2} \cdot F^{C_{3}+1} \cdot d^{C_{4}} \cdot 8.933 \cdot 10^{-4}
\end{aligned}
$$

Differentiating Eq. (45) with respect to piping diameter and solving the derived equation for $d$, optimum economic pipe diameter can be obtained.

$$
\begin{aligned}
& 0=221.5 \cdot 0.55 \cdot d^{-0.45}+C_{2} \cdot F^{C_{3}+1} \cdot 8.933 \cdot 10^{-4} \cdot C_{4} \cdot d^{C_{4}-1} \\
& d=0.023 \cdot F^{0.516}
\end{aligned}
$$

The annualised investment cost for piping $(\$ /(\mathrm{m} \cdot \mathrm{y})) A_{\text {piping }} \cdot(\text { flowrate })^{B_{\text {piping }}}$ was obtained by substituting the economic pipe diameter from equation (46) in Eq. (36) describing annualised piping investment cost. The value for piping cost coefficient is $A_{\text {piping }}=27.89$ and cost exponent for piping is $B_{\text {piping }}=0.284$.

$C_{p i p e}^{(i n v)}=221.5 \cdot d^{0.55}=\left(221.5 \cdot\left(0.023 \cdot F^{0.516}\right)\right)^{0.55}=27.89 \cdot F^{0.284}$ 


\section{RESULTS AND DISSCUSSION}

Three examples were solved in this section in order to illustrate the applicability and effectiveness of the proposed model and solution strategy. Examples of different complexities were considered including single and multiple contaminants, with or without wastewater treatment units and also considering individual and interplant non-isothermal water networks. The parameters values and cost data associated with examples are given in Table 2 and are taken from (Dong et al., 2008).

Table 2 Operating parameters and cost data for the studied examples.

\begin{tabular}{ll}
\hline Parameter & \\
\hline Freshwater temperature $\left(T F W_{s}\right),{ }^{\circ} \mathrm{C}$ & 20 \\
Wastewater temperature $\left(T W W^{\text {(out })}\right),{ }^{\circ} \mathrm{C}$ & 30 \\
Cooling water inlet $(t c u i n)$ and outlet $(t c u o u t)$ temperatures, ${ }^{\circ} \mathrm{C}$ & 10 and 20 \\
Hot utility temperature $($ thuin $),{ }^{\circ} \mathrm{C}$ & 120 \\
Freshwater cost $\left(C F W_{s}\right), \$ / \mathrm{t}$ & 0.375 \\
Hot utility cost $\left(C_{H U}\right), \$ /(\mathrm{kW} \cdot \mathrm{y})$ & 377 \\
Cold utility cost $\left(C_{C U}\right), \$ /(\mathrm{kW} \cdot \mathrm{y})$ & 189 \\
Fixed cost for heat exchangers $(C F), \$$ & 8,000 \\
Area cost coefficient for heat exchangers $\left(C_{i, j}\right)$, heaters $\left(C_{i, H U}\right)$ & 1,200 \\
and coolers $\left(C_{i, C U}\right), \$ / \mathrm{m}^{2}$ & \\
Piping installation cost coefficient $\left(A_{p i p i n g}\right), \$ / \mathrm{m}$ & 27.89 \\
Piping cost exponents $\left(B_{p i p i n g}\right)$ & 0.284 \\
Cost exponent for heat exchangers $(B)$ & 0.6 \\
Individual heat transfer coefficients for water $\left(h_{i,} h_{j}\right)$, hot $\left(h_{H U}\right)$ & 1 \\
and cold $\left(h_{C U}\right)$ utilities, $\mathrm{kW} /\left(\mathrm{m}^{2} \cdot \mathrm{K}\right)$ & \\
Specific heat capacity of water $\left(C_{p}\right), \mathrm{J} /\left(\mathrm{g} \cdot{ }^{\circ} \mathrm{C}\right)$ & 4.2 \\
Plant operating hours $(H), \mathrm{h}$ & 8,000 \\
Annualisation factor for treatment units investment $(A F)$ & 0.1 \\
\hline
\end{tabular}

\subsection{Example 1-single process problem}

Example 1 considers a single contaminant problem including only process water-using units within an individual plant. The operating data of process units (Table 3) were taken from (Bogataj and Bagajewicz, 2008) (Bogataj and Bagajewicz, 2008). The data for the distance between freshwater source, process water-using units and effluent discharge required in order to account for piping installation cost are given in Table 4, arbitrarily. The exchanger minimum approach temperature is $1^{\circ} \mathrm{C}$. 
Table 3 Process units operating data for Example 1.

\begin{tabular}{lllll}
\hline $\begin{array}{l}\text { Process } \\
\text { unit }\end{array}$ & $\begin{array}{l}\text { Contaminant mass } \\
\text { load }\left(M L_{p, c}\right), \mathrm{g} / \mathrm{h}\end{array}$ & $\begin{array}{l}\text { Maximum inlet } \\
\text { concentration } \\
\left(x P U_{p, c}^{(i n, \max )}\right), \mathrm{ppm}\end{array}$ & $\begin{array}{l}\text { Maximum outlet } \\
\text { concentration } \\
\left(x P U_{p, c}^{(\text {out }, \text { max })}\right), \mathrm{ppm}\end{array}$ & $\begin{array}{l}\text { Temperature } \\
\left(T P U_{p}^{(i n)}\right),{ }^{\circ} \mathrm{C}\end{array}$ \\
\hline $\mathrm{PU}_{1}$ & 2000 & 0 & 100 & 40 \\
$\mathrm{PU}_{2}$ & 5000 & 50 & 100 & 100 \\
$\mathrm{PU}_{3}$ & 30,000 & 50 & 800 & 75 \\
$\mathrm{PU}_{4}$ & 4000 & 400 & 800 & 50 \\
\hline
\end{tabular}

Table 4 Distance $(\mathrm{m})$ between superstructure elements: process unit (PU), wastewater discharge (WW) and freshwater source (FW) for Example 1.

\begin{tabular}{lllllll}
\hline Distance* & $\mathrm{FW}$ & $\mathrm{PU}_{1}$ & $\mathrm{PU}_{2}$ & $\mathrm{PU}_{3}$ & $\mathrm{PU}_{4}$ & $\mathrm{WW}$ \\
\hline $\mathrm{PU}_{1}$ & 360 & 0 & 130 & 190 & 280 & 620 \\
$\mathrm{PU}_{2}$ & 330 & & 0 & 60 & 150 & 470 \\
$\mathrm{PU}_{3}$ & 270 & & & 0 & 90 & 420 \\
$\mathrm{PU}_{4}$ & 280 & & & & 0 & 330 \\
$\mathrm{WW}$ & 300 & & & & & 0 \\
\hline
\end{tabular}

*Distance between superstructure elements is the same regardless to the direction of the water flow.

The solution obtained match those found in the literature (Ahmetović and Kravanja, 2013; Bogataj and Bagajewicz, 2008; Ibrić et al., 2014) regarding freshwater usage (25 kg/s) and hot utility consumption $(1050 \mathrm{~kW}$ ). The optimal network design (Fig. 6) consists of one heat exchanger and one heater with the HEN investment cost 134,226 \$/y. The annualised piping installation cost is 116,760 \$/y and the TAC of the network is 916,836 \$/y. The marked fields (dashed rectangle) in the Fig. 6 represent the location of the freshwater source, process water-using units and a wastewater discharge place. The lines crossing the location borders are those for which the piping installation cost is considered. It is important to highlight that the basic network design considering water streams flow rates is unchanged compared to the solutions presented in the literature (Ahmetović and Kravanja, 2013; Ibrić et al., 2014) without piping costs (see Table 5). However, the placements of hot and cold streams and non-isothermal mixing points are important and have impact on the TAC of the network. Note that two networks with the same freshwater, utilities consumption, and HEN investment cost can be obtained but with different piping configuration. Fig. 7 shows an alternative locally optimal solution with the same operating costs and HEN investment cost. However, the piping installation cost for this network is $126,559 \$ / y$ and the TAC $926,635 \$ / y$. 
Table 5 Comparison with the literature results for Example 1.

\begin{tabular}{lllll}
\hline Parameter & $\begin{array}{l}\text { (Bogataj and } \\
\text { Bagajewicz, } \\
2008) *\end{array}$ & $\begin{array}{l}\text { (Ahmetović and } \\
\text { Kravanja, 2013) }\end{array}$ & $\begin{array}{l}\text { (Ibrić et al., } \\
\text { 2014) }\end{array}$ & $\begin{array}{l}\text { This paper } \\
\text { (including } \\
\text { piping) }\end{array}$ \\
\hline Freshwater, kg/s & 25 & 25 & 25 & 25 \\
Hot utility, $\mathrm{kW}$ & 1050 & 1050 & 1050 & 1050 \\
Cold utility, $\mathrm{kW}$ & 0 & 0 & 0 & 0 \\
Heat exchangers & 3 & 2 & 2 & 2 \\
Piping investment cost, \$/y & - & - & - & 116,760 \\
HEN investment, \$/y & 146,748 & 134,226 & 134,226 & 134,226 \\
TAC without piping, $\$$ /y & 812,598 & 800,077 & 800,077 & 800,077 \\
TAC including piping, \$/y & - & - & - & 916,836 \\
\hline
\end{tabular}

*Recalculated data taken from (Ahmetović and Kravanja, 2013)

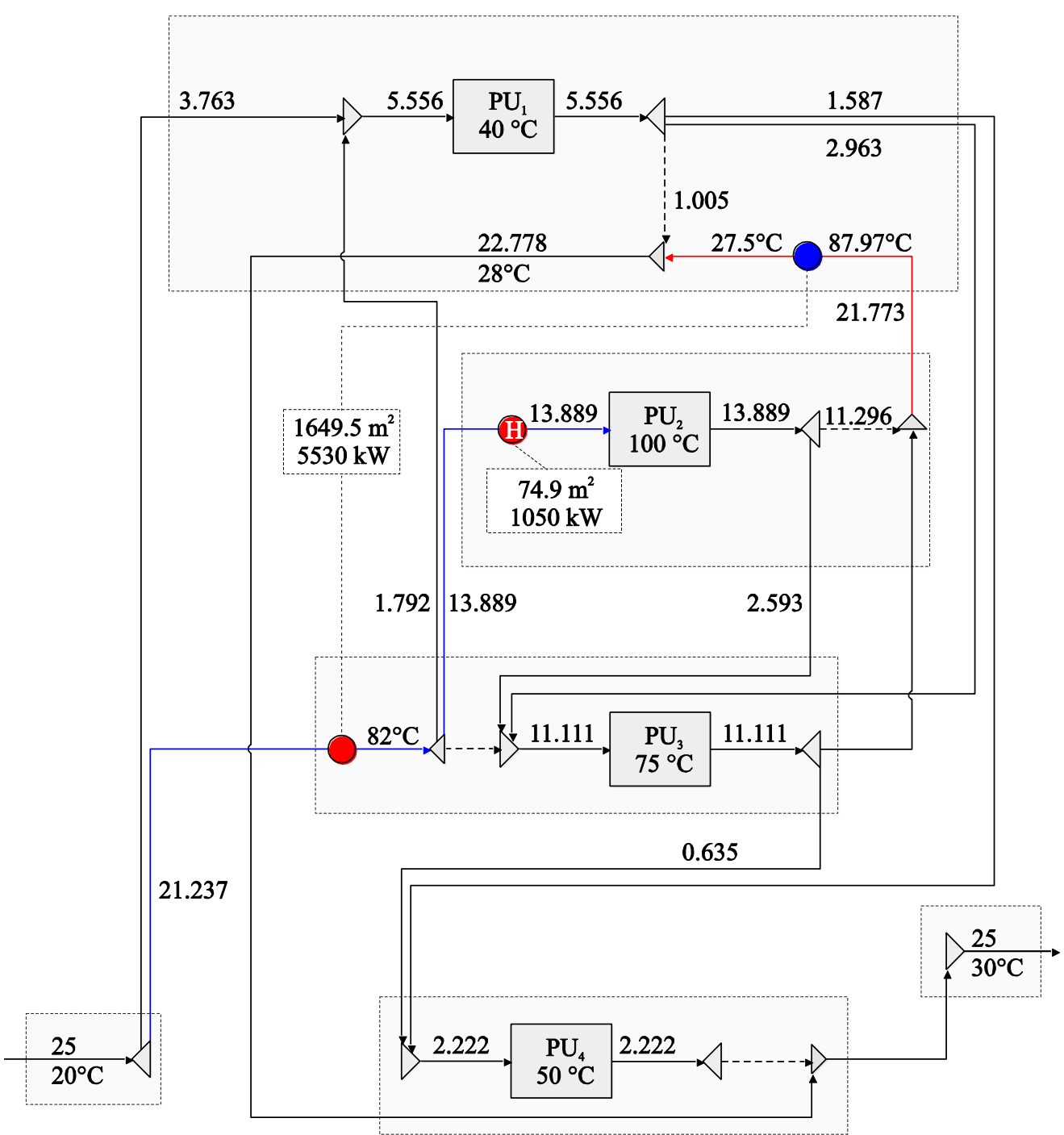

Fig. 6. Optimal network design for Example 1 (single process problem). 


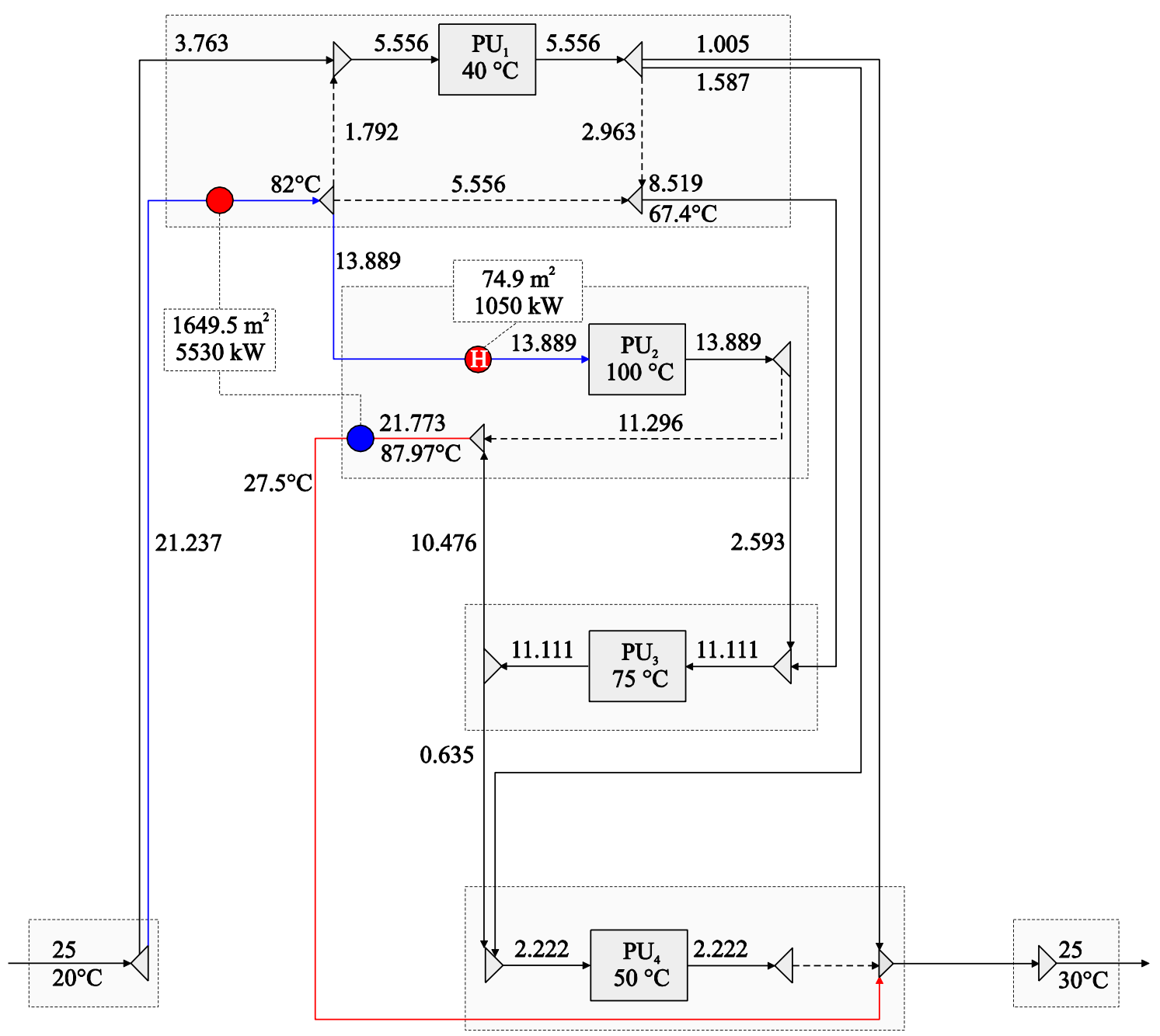

Fig. 7. An alternative network design for Example 1.

\subsection{Example 2-multicontaminant interplant problem}

Example 2 was solved in order to demonstrate the water and heat integration options available within the proposed model. A multi-contaminant case study consisting of four process water-using units (Bogataj and Bagajewicz, 2008) was considered. However, we assumed that two process units $\mathrm{PU}_{1}$ and $\mathrm{PU}_{2}$ exist within Plant 1, and process units $\mathrm{PU}_{3}$ and $\mathrm{PU}_{4}$ within Plant 2. Data for the process water- using units are given in Table 6. Two cases were considered. In the first case (Case a) the water and heat integration options within the process water-using units corresponding to different plants are disabled. Case $\mathrm{b}$ considers water integration between different plants. However, in both cases heat integration between hot/cold streams within different plants was not considered. The exchanger minimum approach temperature is $1{ }^{\circ} \mathrm{C}$ and the same distance matrix was used as in Example 1. 
Table 6 Process units operating data for Example 2.

\begin{tabular}{|c|c|c|c|c|c|c|c|c|c|c|}
\hline \multirow[t]{2}{*}{$\begin{array}{l}\text { Plant- } \\
\text { Process } \\
\text { unit }\end{array}$} & \multicolumn{3}{|c|}{$\begin{array}{l}\text { Contaminant mass load } \\
\left(M L_{p, c}\right), \mathrm{g} / \mathrm{h}\end{array}$} & \multicolumn{3}{|c|}{$\begin{array}{l}\text { Maximum inlet } \\
\text { concentration } \\
\left(x P U_{p, c}^{(i n, \max )}\right), \mathrm{ppm}\end{array}$} & \multicolumn{3}{|c|}{$\begin{array}{l}\text { Maximum outlet } \\
\text { concentration } \\
\left(x P U_{p, c}^{(\text {out }, \text { max })}\right), \mathrm{ppm}\end{array}$} & \multirow[t]{2}{*}{$\begin{array}{l}\text { Temperature } \\
\left(T P U_{p}^{(i n)}\right),{ }^{\circ} \mathrm{C}\end{array}$} \\
\hline & $\mathrm{A}$ & B & $\mathrm{C}$ & A & B & $\mathrm{C}$ & $\mathrm{A}$ & $\mathrm{B}$ & $\mathrm{C}$ & \\
\hline $1-\mathrm{PU}_{1}$ & 2000 & 1000 & 3000 & 0 & 15 & 0 & 100 & 100 & 100 & 40 \\
\hline $1-\mathrm{PU}_{2}$ & 5000 & 0 & 15,000 & 5 & 100 & 30 & 100 & 200 & 250 & 100 \\
\hline $2-\mathrm{PU}_{3}$ & 30,000 & 4000 & 0 & 100 & 100 & 100 & 800 & 750 & 600 & 75 \\
\hline 2-PU 4 & 4000 & 22,000 & 17,000 & 400 & 380 & 250 & 800 & 800 & 800 & 50 \\
\hline
\end{tabular}

The network exhibited the minimum freshwater consumption $(35.883 \mathrm{~kg} / \mathrm{s})$ with $21.591 \mathrm{~kg} / \mathrm{s}$ of freshwater consumed within Plant 1 and $14.292 \mathrm{~kg} / \mathrm{s}$ within Plant 2. A corresponding total consumption of hot and cold utilities for both plants is $1507 \mathrm{~kW}$ and $0 \mathrm{~kW}$. As shown in Fig. 8, water integration between plants is disabled and water reuse options within Plant $1\left(\mathrm{PU}_{1} \rightarrow \mathrm{PU}_{2}\right)$ and Plant $2\left(\mathrm{PU}_{3} \rightarrow \mathrm{PU}_{4}\right.$ and $\mathrm{PU}_{4} \rightarrow \mathrm{PU}_{3}$ ) exist. The optimal network design consists of five heat exchangers (three within Plant 1 and two within Plant 2) with a heat exchanger investment cost of 237,838 \$/y. The piping investment cost is $163,986 \$ / y$ and TAC of the network is $1,357,522 \$ / y$.

Furthermore, the Case b considers water integration between plants, as well as heat integration by direct stream mixing (non-isothermal mixing) but excludes the option of heat exchange through heat exchangers between streams from separate plants. In contrast to previous options, further reduction of freshwater consumption is now possible owing to additional options being available for water reuse between plants. The optimal design of the interplant network exhibited the minimum freshwater consumption of $26.535 \mathrm{~kg} / \mathrm{s}$ and a corresponding hot utility consumption of $1114.5 \mathrm{~kW}$. Freshwater consumption was reduced by $25.6 \%$ (35.883 vs. $26.535 \mathrm{~kg} / \mathrm{s}$ ) when compared to Case a. Direct water integration of water streams between plants significantly reduces freshwater and utilities consumption owing to the increase in water reuse opportunities. Also, a significant reduction in the number of heat exchangers occurs because of the additionally enabled non-isothermal mixing options and consequent increase in the heat loads of individual heat exchangers. 


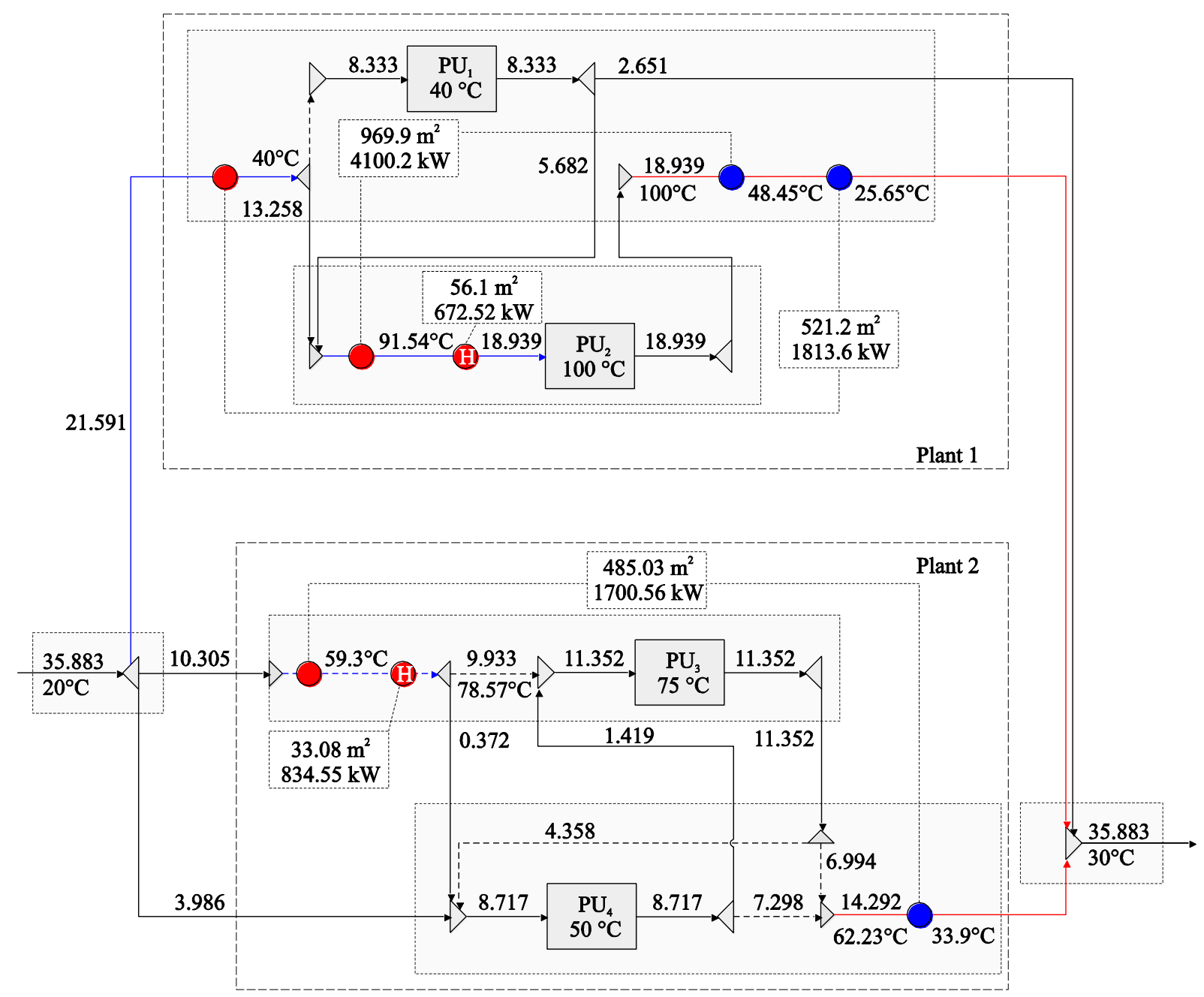

Fig. 8. Optimal network design for Example 2 (Case a-stand-alone processes).

Fig. 9 shows the optimal network design for Example 2 (Case b). The optimal interplant network design for Case b consists of only two heat exchangers and one heater with a HEN investment cost of 177,654 $\$ / y$. Compared to the case without direct water integration (Case a) additional piping investment cost is required for interplant connections (approximately $8 \%$ increase). The total annual cost of the network is $1,007,805 \$$ /y including piping investment cost. Fig. 10 shows the optimal network design obtained by using proposed model, however excluding piping cost. As can be seen from Fig. 10 the optimal network design layout is somewhat different, and more complex, from the design obtained when including piping cost. The network (Fig. 10) included more splitting and mixing option with the increased number of connections compared to network design in Fig.9.

Note that the same case study was considered as a single plant consisting of four water-using units studied within the literature. Table 7 presents a comparison of the results obtained in this work with the literature results for Case b. The TAC of the network design without piping cost is in a good agreement with the literature results. 


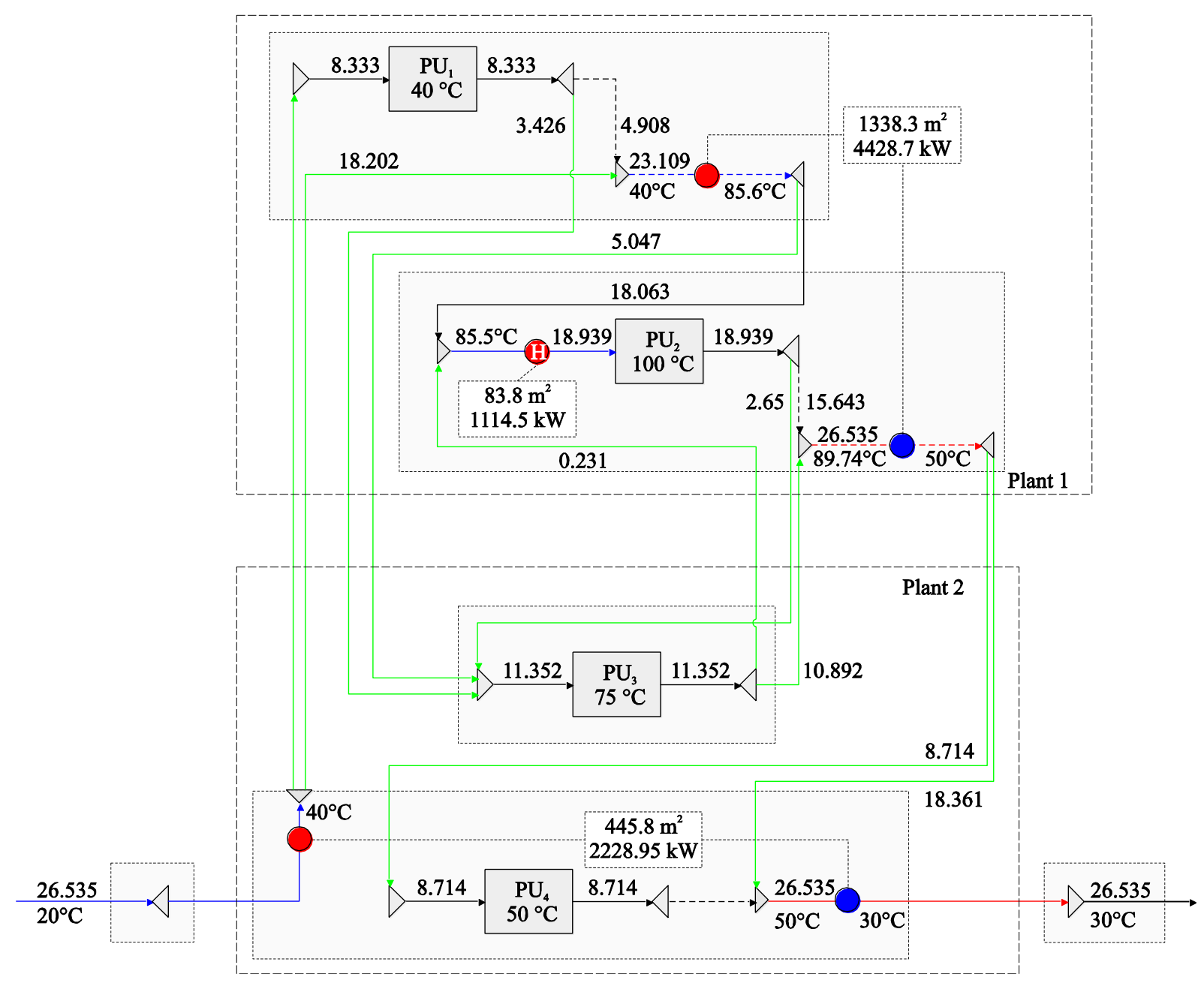

Fig. 9. Optimal network design for Example 2 (Case b-direct water integration including piping). 
Table 7 Comparison with the literature results for Example 2 (Case b-direct water integration).

\begin{tabular}{lllllll}
\hline Parameter & $\begin{array}{l}\text { (Bogataj and } \\
\text { Bagajewicz, } \\
2008)^{*}\end{array}$ & $\begin{array}{l}\text { (Ahmetović } \\
\text { and Kravanja, } \\
\text { 2014) }\end{array}$ & $\begin{array}{l}\text { (Yan et } \\
\text { al., 2016) }\end{array}$ & $\begin{array}{l}\text { (Ibrić et al., } \\
\text { 2016) }\end{array}$ & $\begin{array}{l}\text { This paper } \\
\text { (without } \\
\text { piping) }\end{array}$ & $\begin{array}{l}\text { This paper } \\
\text { (including } \\
\text { piping) }\end{array}$ \\
\hline $\begin{array}{l}\text { Freshwater, } \\
\text { kg/s }\end{array}$ & 26.535 & 26.535 & 26.716 & 26.535 & 26.535 & 26.535 \\
$\begin{array}{l}\text { Hot utility, } \\
\text { kW }\end{array}$ & 1115.7 & 1114.5 & 1122.1 & 1114.5 & 1114.5 & 1114.5 \\
$\begin{array}{l}\text { Cold utility, } \\
\text { kW }\end{array}$ & 0 & 0 & 0 & 0 & 0 & 0 \\
$\begin{array}{l}\text { Heat } \\
\text { exchangers }\end{array}$ & 4 & 4 & 4 & 3 & 3 & 3 \\
$\begin{array}{l}\text { Piping } \\
\text { investment } \\
\text { cost, \$/y }\end{array}$ & - & - & - & - & - & 123,151 \\
$\begin{array}{l}\text { HEN } \\
\text { investment, }\end{array}$ & 199,861 & 183,063 & 183,107 & 177,859 & 177,859 & 177,654 \\
$\begin{array}{l}\text { \$/y } \\
\text { TAC without } \\
\text { piping, \$/y }\end{array}$ & 907,066 & 889,772 & 894,658 & 884,595 & 884,595 & 884,919 \\
\hline
\end{tabular}

*Recalculated data taken from the literature (Ahmetović and Kravanja, 2014) 


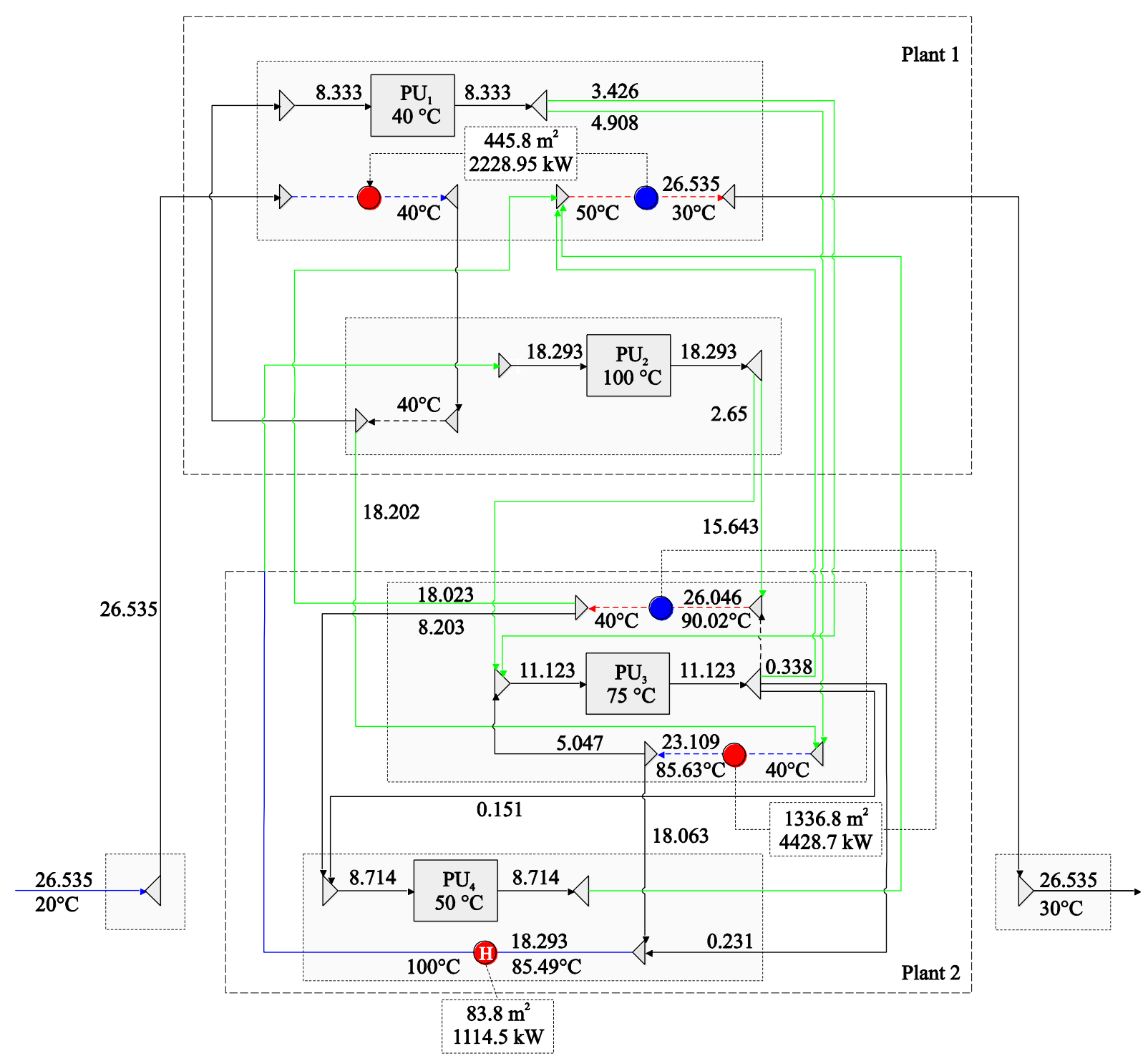

Fig. 10. Optimal network design for Example 2 (Case b-direct water integration without piping).

\subsection{Example 3-interplant problem including wastewater treatment}

Example 3 considers a single contaminant problem now including wastewater treatment units enabling wastewater regeneration and reuse. The operating data for the process water-using units were taken from the literature (Zhou et al., 2012b) are shown in Table 8. Two classes of wastewater treatment units are available for both plants. The operating temperature of the treatment units is $30^{\circ} \mathrm{C}$ with removal ratios of contaminant within the treatment units of $95 \%$ and $90 \%$. Treatment units capital cost (\$) as a function of the wastewater flow-rate $(\mathrm{t} / \mathrm{h})$ are given as $16,800 \cdot F^{0.7}$ and $12,600 \cdot F^{0.7}$, whilst the corresponding operating cost $(\$ / y)$ are $1 \cdot F$ and $0.76 \cdot F$. The maximum contaminant concentration in the effluent stream discharged into the environment is $20 \mathrm{ppm}$. In addition, the distance matrix is given in Table 9, arbitrarily. The exchanger minimum approach temperature is $10^{\circ} \mathrm{C}$. 
Table 8 Process units operating data for Example 3.

\begin{tabular}{llllll}
\hline Plant & $\begin{array}{l}\text { Process } \\
\text { unit }\end{array}$ & $\begin{array}{l}\text { Contaminant } \\
\text { mass load } \\
\left(M L_{p, c}\right), \mathrm{g} / \mathrm{h}\end{array}$ & $\begin{array}{l}\text { Maximum inlet } \\
\text { concentration } \\
\left(x P U_{p, c}^{(i, \text { max })}\right), \mathrm{ppm}\end{array}$ & $\begin{array}{l}\text { Maximum outlet } \\
\text { concentration } \\
\left(x P U_{p, c}^{(\text {out,max })}\right), \mathrm{ppm}\end{array}$ & $\begin{array}{l}\text { Temperature } \\
\left(T P U_{p}^{(\text {in })}\right),{ }^{\circ} \mathrm{C}\end{array}$ \\
\hline Plant 1 & $\mathrm{PU}_{1}$ & 2 & 0 & 100 & 40 \\
& $\mathrm{PU}_{2}$ & 5 & 50 & 100 & 100 \\
& $\mathrm{PU}_{3}$ & 30 & 50 & 800 & 75 \\
& $\mathrm{PU}_{4}$ & 4 & 400 & 800 & 50 \\
\hline Plant 2 & $\mathrm{PU}_{5}$ & 5 & 50 & 100 & 100 \\
& $\mathrm{PU}_{6}$ & 30 & 50 & 800 & 75 \\
& $\mathrm{PU}_{7}$ & 50 & 800 & 1100 & 100 \\
\hline
\end{tabular}

Table 9 Distance $(\mathrm{m})$ between superstructure elements: process unit (PU), wastewater discharge (WW) and freshwater source (FW) for Example 3.

\begin{tabular}{llllllllllll}
\hline Distance* & $\mathrm{FW}$ & $\mathrm{PU}_{1}$ & $\mathrm{PU}_{2}$ & $\mathrm{PU}_{3}$ & $\mathrm{PU}_{4}$ & $\mathrm{PU}_{5}$ & $\mathrm{PU}_{6}$ & $\mathrm{PU}_{7}$ & $\mathrm{TU}_{1}$ & $\mathrm{TU}_{2}$ & $\mathrm{WW}$ \\
\hline $\mathrm{PU}_{1}$ & 360 & 0 & 130 & 190 & 280 & 450 & 550 & 600 & 510 & 560 & 620 \\
$\mathrm{PU}_{2}$ & 330 & & 0 & 60 & 150 & 320 & 420 & 470 & 380 & 420 & 470 \\
$\mathrm{PU}_{3}$ & 270 & & & 0 & 90 & 260 & 360 & 410 & 320 & 370 & 420 \\
$\mathrm{PU}_{4}$ & 280 & & & & 0 & 170 & 270 & 320 & 230 & 280 & 330 \\
$\mathrm{PU}_{5}$ & 230 & & & & & 0 & 100 & 150 & 390 & 340 & 310 \\
$\mathrm{PU}_{6}$ & 330 & & & & & & 0 & 50 & 290 & 240 & 210 \\
$\mathrm{PU}_{7}$ & 380 & & & & & & & 0 & 340 & 290 & 260 \\
$\mathrm{TU}_{1}$ & 500 & & & & & & & & 0 & 50 & 100 \\
$\mathrm{TU}_{2}$ & 450 & & & & & & & & 50 & 0 & 50 \\
$\mathrm{WW}$ & 300 & & & & & & & & & & 0 \\
\hline
\end{tabular}

*Distance between superstructure elements is the same regardless to the direction of the water flow.

The freshwater consumption within the network design presented by Zhou et al. (2012b) is $228.77 \mathrm{~kg} / \mathrm{s}$ with the corresponding consumptions of the hot and cold utilities 9608 and $0 \mathrm{~kW}$, respectively. The TAC of the network is $12,147,257 \$ / y$ and excluding piping costs for considering the interplant connections is $11,814,113 \$ / y$. Fig. 11 shows the optimal network design obtained using the proposed model and solution strategy. The freshwater consumption is reduced (186.956 vs. $228.77 \mathrm{~kg} / \mathrm{s})$ by approximately $18 \%$ as well as the hot utility consumption (7852.2 vs. $9608 \mathrm{~kW})$. However, the optimal network design in this paper exhibited higher investment cost of heat exchangers $(520,753$ vs. 435,400$)$ with total number of five exchangers compared to the design with three heat exchangers (Zhou et al., $2012 b)$. Also the treatment unit operating and investment cost are higher $(5,544,650$ vs. 5,285,839 \$/y). Nevertheless, the TAC of the network in this paper is still lower $(11,044,803$ vs. $11,814,113 \$ / y)$ when not considering piping cost. The piping installation cost for the network design shown in Fig. 10 is $514,030 \$ / y$ and the TAC of the network including piping is $11,558,833 \$ / y$. Note that Zhou et al. (2012b) considered only pipeline for cross plant connections using different cost functions. For that reason the piping installation costs were not compared. 


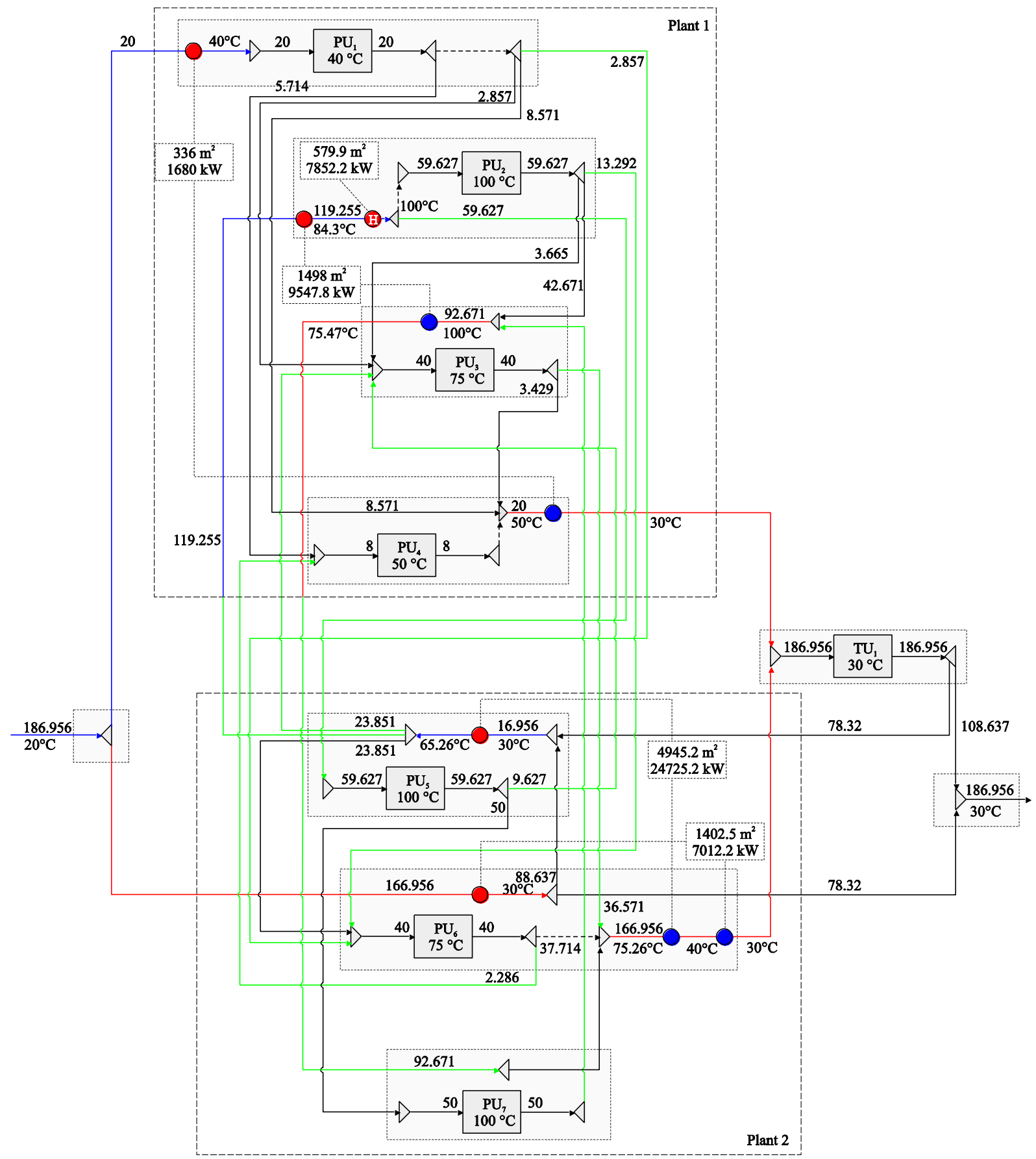

Fig. 11. Optimal network design for Example 3 (direct water integration including wastewater treatment). 


\section{CONCLUSIONS}

This paper has presented an approach for the synthesis of both single and interplant non-isothermal water networks. Binary parameters were used in order to define the connections between process water-using units, wastewater treatment units associated with different plants as well as to identify allowed matches between hot and cold streams. The objective function of the proposed MINLP model includes the piping installation cost for the connection within individual plants as well as cross plant connections. The model was solved by using a recently proposed two-step iterative solution strategy (Ibrić et al., 2016) consisting of initialisation and design steps. Three examples were solved in order to demonstrate the model capabilities for solving problems of different complexities involving single and interplant water networks. It was clearly shown that a significant savings in water and utilities (more that $25 \%$ in Example 2) and consequently investment cost can be achieved by enabling water and heat integration options between plants.

\section{ACKNOWLEDGEMENTS}

The authors are grateful to the Swiss National Science Foundation (SNSF) and the Swiss Agency for Development and Cooperation (SDC) for providing financial support within the SCOPES 2013-2016 (Scientific Co-operation between Eastern Europe and Switzerland) joint research project (CAPEEWWR: IZ73Z0_152622/1) as well as support from the Slovenian Research Agency (Program No. P20032), and Erasmus Mundus Action 2-JoinEU SEE Penta programme.

\section{Notations}

Indices

c Contaminant

$i \quad$ Hot process stream

j $\quad$ Cold process stream

$p \quad$ Process unit

$s \quad$ Freshwater source

$t \quad$ Treatment unit

pl Plant

Sets

$C P \quad$ Cold process stream

$H P$ Hot process stream

$P U$ Process unit

$S C \quad$ Contaminant 
SFW Freshwater source

TU Treatment unit

PLT Plant

\section{Parameters}

$A F \quad$ Treatment investment annualisation factor

$A_{\text {piping }} \quad$ Piping annualised cost coefficient

B Cost exponent for heat exchangers

$B_{\text {piping }} \quad$ Cost exponent for piping installation cost

$C_{C U} \quad$ Cold utility cost, $\$ /(\mathrm{W} \cdot \mathrm{y})$

CF Fixed charge for heat exchangers, $\$$

$C F W_{s} \quad$ Freshwater cost, $\$ / \mathrm{kg}$

$C_{H U} \quad$ Hot utility cost, $\$(\mathrm{~W} \cdot \mathrm{y})$

$C_{i, C U} \quad$ Area cost coefficient for coolers, $\$ / \mathrm{m}^{2}$

$C_{i, H U} \quad$ Area cost coefficient for heaters, $\$ / \mathrm{m}^{2}$

$C_{i, j} \quad$ Area cost coefficient for heat exchangers, $\$ / \mathrm{m}^{2}$

$C_{p} \quad$ Specific heat capacity of water, $\mathrm{J} /(\mathrm{kg} \cdot \mathrm{K})$

EMAT Exchanger minimum approach temperature, $\mathrm{K}$

$H \quad$ Plant annual operating hours, $\mathrm{h}$

$h_{C U} \quad$ Cold utility individual heat transfer coefficient, $\mathrm{W} /\left(\mathrm{m}^{2} \cdot \mathrm{K}\right)$

$h_{H U} \quad$ Hot utility individual heat transfer coefficient, $\mathrm{W} /\left(\mathrm{m}^{2} \cdot \mathrm{K}\right)$

$h_{i} \quad$ Hot water stream $i$ individual heat transfer coefficient $i, \mathrm{~W} /\left(\mathrm{m}^{2} \cdot \mathrm{K}\right)$

$h_{j} \quad$ Cold water stream $j$ individual heat transfer coefficient $j, \mathrm{~W} /\left(\mathrm{m}^{2} \cdot \mathrm{K}\right)$

HRAT Heat recovery approach temperature, $\mathrm{K}$

$I C_{t}$

Investment cost coefficient for treatment unit $t, \$ / \mathrm{kg}$

$O C_{t} \quad$ Operating cost coefficient for treatment unit $t, \$ / \mathrm{kg}$

tcuin Cold utility inlet temperature, $\mathrm{K}$

tcuout Cold utility outlet temperature, $\mathrm{K}$

thuin Hot utility inlet temperature, $\mathrm{K}$

thuout Hot utility outlet temperature, $\mathrm{K}$

$U \quad$ Overall heat transfer coefficient, $\mathrm{W} /\left(\mathrm{m}^{2} \cdot \mathrm{K}\right)$

$\alpha_{t} \quad$ Cost exponent for treatment unit $t$

$x F W_{s, c} \quad$ Concentration of contaminant $c$ in freshwater source $s, \mathrm{ppm}$

$x P U_{p, c}^{(i n, \max )} \quad$ Maximum concentration of contaminant $c$ at the inlet to process unit $p, \mathrm{ppm}$

$x P U_{p, c}^{(\text {out, } \max )} \quad$ Maximum concentration of contaminant $c$ at the outlet from process unit $p, \mathrm{ppm}$ 

$T P U_{p}^{(i n)} \quad$ Process unit $p$ inlet temperature, $\mathrm{K}$
$T T U_{t}^{(i n)} \quad$ Treatment unit $t$ inlet temperature, $\mathrm{K}$
$T P U_{p}^{(o u t)} \quad$ Process unit $p$ outlet temperature, $\mathrm{K}$
$T T U_{t}^{(o u t)} \quad$ Treatment unit $t$ outlet temperature, $\mathrm{K}$
$T F W_{s} \quad$ Temperature of the freshwater source $s, \mathrm{~K}$
$T W W^{(\text {out })} \quad$ Temperature of wastewater discharged into the environment, $\mathrm{K}$
$M L_{p, c} \quad$ Mass load of the contaminant $c$ in process unit $p, \mathrm{~kg} / \mathrm{s}$
$L S P_{s, p} \quad$ Distance between freshwater source $s$ and process unit $p, \mathrm{~m}$
$L S T_{s, t} \quad$ Distance between freshwater source $s$ and wastewater treatment unit $t, \mathrm{~m}$
$L S E_{s} \quad$ Distance of freshwater source $s$ from the effluent discharge place, $\mathrm{m}$
$L P E_{p} \quad$ Distance between process unit $p$ and the effluent discharge place, $\mathrm{m}$
$L T E_{t} \quad$ Distance between wastewater treatment unit $t$ and the effluent discharge place, $\mathrm{m}$
$L P P_{p, p^{\prime}} \quad$ Distance between process units $p$ and $p^{\prime}, \mathrm{m}$
$L P T_{p, t} \quad$ Distance between process units $p$ and wastewater treatment unit $t, \mathrm{~m}$
$L T T_{t, t^{\prime}} \quad$ Distance wastewater treatment unit $t$ and $t^{\prime}, \mathrm{m}$
$N_{S T U} \quad$ Number of treatment units allowed to be selected
$R R_{t, c} \quad$ Removal ratio of contaminant $c$ in treatment unit $t, \% / 100$
$\Gamma \quad$ Upper bound for driving force
Re Reynolds number
$\Delta p \quad$ Fluid pressure drop, $\mathrm{Pa}$
$v \quad$ Fluid velocity, $\mathrm{m} / \mathrm{s}$
$L \quad$ Pipe length, $\mathrm{m}$
d Pipe diameter, $\mathrm{m}$
$\rho \quad$ Water density, $\mathrm{kg} / \mathrm{m}^{3}$
$\mu \quad$ Water dynamic viscosity, $\mathrm{Pa} \cdot \mathrm{s}$
$\lambda \quad$ Pipe friction coefficient
$C_{\text {pipe }}^{(O P E R)} \quad$ Pipe operating cost, $\$ / \mathrm{y}$
$C_{\text {pipe }}^{(I N V)} \quad$ Pipe investment cost, $\$ / \mathrm{y}$
$C_{e l} \quad$ Cost of electricity, $\$ /(\mathrm{kW} \cdot \mathrm{h})$
$\eta_{\text {pump }} \quad$ Pump efficiency
$Y P P\left(p, p^{\prime}\right) \quad$ Binary parameter for identification of connection between unit $p$ and $p^{\prime}$ 


$\begin{array}{ll}Y T T\left(t, t^{\prime}\right) & \text { Binary parameter for identification of connection between unit } t \text { and } t^{\prime} \\ Y P T(p, t) & \text { Binary parameter for identification of connection between unit } p \text { and } t \\ H X(i, j) & \text { Binary parameter for defining the match between hot stream } i \text { and cold stream } j \\ N P U_{p l} & \text { Number of last process unit within the plant } p l \\ N T U_{p l} & \text { Number of last treatment unit within the plant } p l\end{array}$

\section{Continuous variables}

$F W_{s} \quad$ Freshwater flow rate from source $s, \mathrm{~kg} / \mathrm{s}$

FIP $P_{s, p} \quad$ Freshwater flow rate from source $s$ to process unit $p, \mathrm{~kg} / \mathrm{s}$

$F I T_{s, t} \quad$ Freshwater flow rate from source $s$ to treatment unit $t, \mathrm{~kg} / \mathrm{s}$

FIHS $S_{s, p} \quad$ Freshwater flow rate from source $s$ to cooling stage $p, \mathrm{~kg} / \mathrm{s}$

FICS $_{s, p} \quad$ Freshwater flow rate from source $s$ to heating stage $p, \mathrm{~kg} / \mathrm{s}$

FIE $\quad$ Freshwater flow rate from source $s$ to final wastewater mixer, $\mathrm{kg} / \mathrm{s}$

FHS $_{p} \quad$ Water flow rate at the cooling stage $p, \mathrm{~kg} / \mathrm{s}$

$F P H S_{p, p^{\prime}} \quad$ Water flow rate from process unit $p$ to cooling stage $p^{\prime}, \mathrm{kg} / \mathrm{s}$

FTHS $_{t, p} \quad$ Water flow rate from treatment unit $t$ to cooling stage $p, \mathrm{~kg} / \mathrm{s}$

$F R H S_{p^{\prime}, p} \quad$ Water flow rate from cooling stage $p^{\prime}$ to cooling stage $p, \mathrm{~kg} / \mathrm{s}$

FCSHS $_{p, p^{\prime}} \quad$ Water flow rate from heating stage $p$ to cooling stage $p^{\prime}, \mathrm{kg} / \mathrm{s}$

$F C S_{p} \quad$ Water flow rate at the heating stage $p, \mathrm{~kg} / \mathrm{s}$

FPCS $_{p, p^{\prime}} \quad$ Water flow rate from process unit $p$ to heating stage $p^{\prime}, \mathrm{kg} / \mathrm{s}$

FTCS $_{t, p} \quad$ Water flow rate from treatment unit $t$ to heating stage $p, \mathrm{~kg} / \mathrm{s}$

$F R C S_{p^{\prime}, p} \quad$ Water flow rate from heating stage $p^{\prime}$ to heating stage $p, \mathrm{~kg} / \mathrm{s}$

$F H S P_{p^{\prime}, p} \quad$ Water flow rate from cooling stage $p^{\prime}$ to process unit $p, \mathrm{~kg} / \mathrm{s}$

$F \quad$ Water flow rate from cooling stage $p$ to treatment $t, \mathrm{~kg} / \mathrm{s}$

FHSCS $_{p^{\prime}, p} \quad$ Water flow rate from cooling stage $p^{\prime}$ to heating stage $p, \mathrm{~kg} / \mathrm{s}$

FHSE $_{p} \quad$ Water flow rate from cooling stage $p$ to wastewater mixer, $\mathrm{kg} / \mathrm{s}$

$F_{C S P} P_{p^{\prime}, p} \quad$ Water flow rate from heating stage $p^{\prime}$ to process unit $p, \mathrm{~kg} / \mathrm{s}$

$F C S T_{p, t} \quad$ Water flow rate from heating stage $p$ to treatment unit $t, \mathrm{~kg} / \mathrm{s}$

$F C S E_{p} \quad$ Water flow rate from heating stage $p$ to wastewater mixer, $\mathrm{kg} / \mathrm{s}$ 


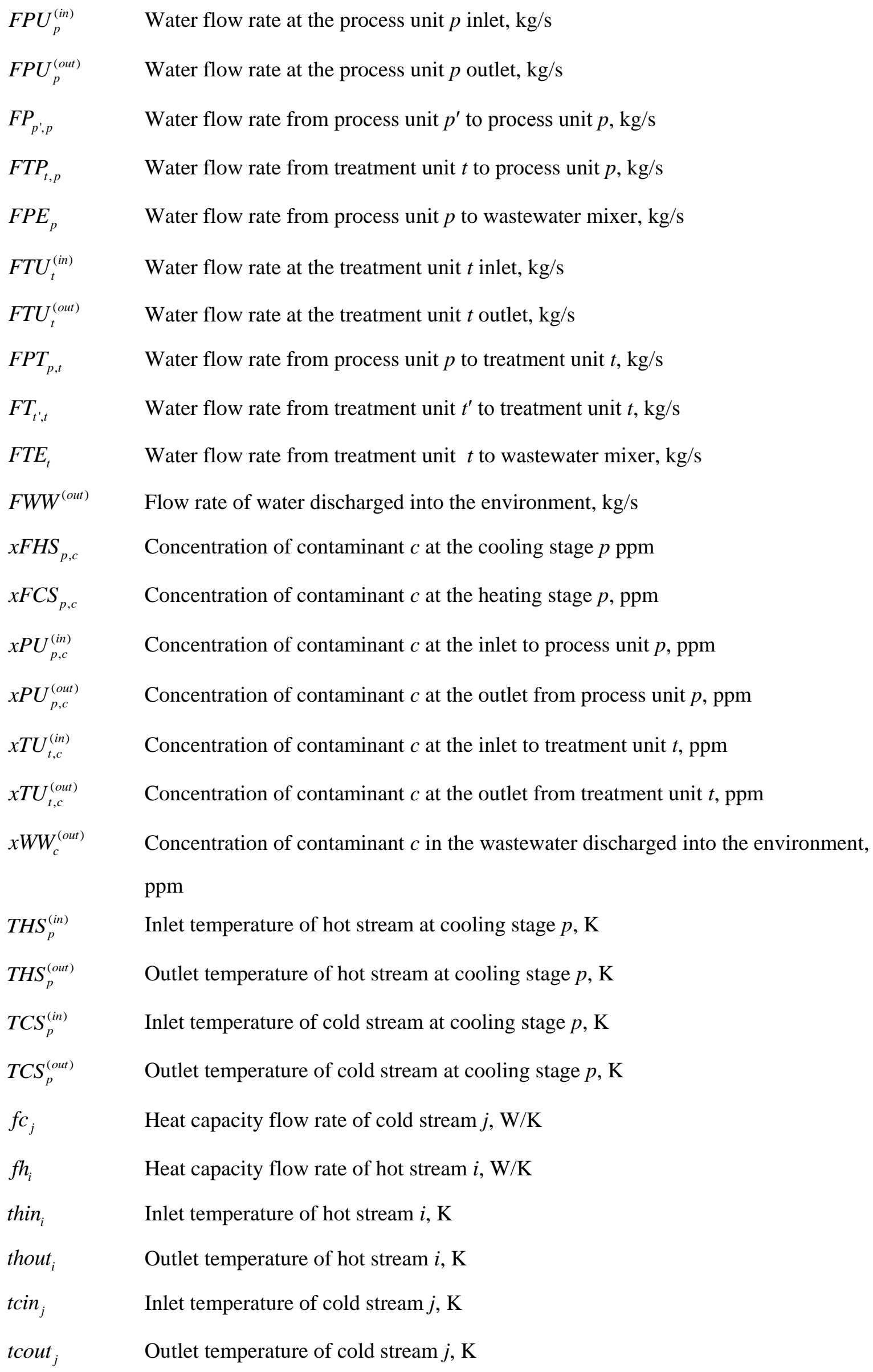




$\begin{array}{ll}q h u & \text { Hot utility load, W } \\ q c u & \text { Cold utility load, W } \\ e c h_{i} & \text { Heat content of hot stream } i, \mathrm{~W} \\ e c c_{j} & \text { Heat content of cold stream } j, \mathrm{~W} \\ q c_{i} & \text { Heat exchanged between hot stream } i \text { with the cold utility, W } \\ q h_{j} & \text { Heat exchanged between cold stream } j \text { with the hot utility, W } \\ q_{i, j, k} & \text { Heat exchanged between hot stream } i \text { and cold stream } j \text { in stage } k, \mathrm{~W} \\ t h_{i, k} & \text { Temperature of hot stream } i \text { at the temperature location } k, \mathrm{~K} \\ t c_{j, k} & \text { Temperature of cold stream } j \text { at the temperature location } k, \mathrm{~K} \\ \Delta t_{i, j, k} & \text { Temperature approach between hot } i \text { and cold } j \text { at temperature location } k, \mathrm{~K} \\ \Delta t h u_{j} & \text { Temperature approach between hot utility and cold stream } j, \mathrm{~K} \\ \Delta t c u_{i} & \text { Temperature approach between cold utility and hot stream } i, \mathrm{~K}\end{array}$

\section{Binary variables}

$z_{i, j, k} \quad$ Existence of match $(i, j)$ in stage $k$

$z c u_{i} \quad$ Existence of match between hot stream $i$ and cold utility

$z h u_{j} \quad$ Existence of match between cold stream $j$ and hot utility

$y T U_{t} \quad$ Existence of treatment unit $t$

Subscripts, superscripts, abbreviations

CU Cold utility

GAMS General Algebraic Modelling System

HEN Heat exchanger network

HU Hot utility

in Inlet

L Lower bound

LMTD Logarithmic mean temperature difference

LP Linear program

LV Level value

$\max \quad$ Maximum

MILP Mixed integer linear program

MINLP Mixed integer nonlinear program

NLP Nonlinear program 


$\begin{array}{ll}\text { out } & \text { Outlet } \\ \text { TAC } & \text { Total annual cost } \\ \text { U } & \text { Upper bound } \\ \text { WN } & \text { Water network } \\ \text { WTN } & \text { Wastewater treatment network }\end{array}$

\section{REFERENCES}

Agana, B.A., Reeve, D., Orbell, J.D., 2013. An approach to industrial water conservation - A case study involving two large manufacturing companies based in Australia. J. Environ. Manage. 114, 445460. doi:http://doi.org/10.1016/j.jenvman.2012.10.047

Ahmetović, E., Ibrić, N., Kravanja, Z., Grossmann, I.E., 2015. Water and energy integration: A comprehensive literature review of non-isothermal water network synthesis. Comput. Chem. Eng. 82, 144-171. doi:10.1016/j.compchemeng.2015.06.011

Ahmetović, E., Kravanja, Z., 2014. Simultaneous optimization of heat-integrated water networks involving process-to-process streams for heat integration. Appl. Therm. Eng. 62, 302-317. doi:10.1016/j.applthermaleng.2013.06.010

Ahmetović, E., Kravanja, Z., 2013. Simultaneous synthesis of process water and heat exchanger networks. Energy 57, 236-250. doi:10.1016/j.energy.2013.02.061

Amidpour, M., Polley, G.T., 1997. Application of Problem Decomposition in Process Integration. Chem. Eng. Res. Des. 75, 53-63. doi:10.1205/026387697523390

Bagajewicz, M., Rodera, H., Savelski, M., 2002. Energy efficient water utilization systems in process plants. Comput. Chem. Eng. 26, 59-79. doi:http://doi.org/10.1016/S0098-1354(01)00751-7

Biegler, L.T., Grossmann, I.E., Westerberg, A.W., 1997. Systematic methods of chemical process design. Prentice-Hall, New Jersey.

Bogataj, M., Bagajewicz, M.J., 2008. Synthesis of non-isothermal heat integrated water networks in chemical processes. Comput. Chem. Eng. 32, 3130-3142. doi:10.1016/j.compchemeng.2008.05.006

Chen, C.-L., Hung, S.-W., Lee, J.-Y., 2010. Design of inter-plant water network with central and decentralized water mains. Comput. Chem. Eng. 34, 1522-1531. doi:10.1016/j.compchemeng.2010.02.024

Cherchi, C., Badruzzaman, M., Oppenheimer, J., Bros, C.M., Jacangelo, J.G., 2015. Energy and water quality management systems for water utility's operations: A review. J. Environ. Manage. 153, 108-120. doi:http://doi.org/10.1016/j.jenvman.2015.01.051

Chew, I.M.L., Foo, D.C.Y., 2009. Automated targeting for inter-plant water integration. Chem. Eng. J. 
153, 23-36. doi:10.1016/j.cej.2009.05.026

Dong, H.-G., Lin, C.-Y., Chang, C.-T., 2008. Simultaneous optimization approach for integrated waterallocation and heat-exchange networks. Chem. Eng. Sci. 63, 3664-3678. doi:10.1016/j.ces.2008.04.044

Duran, M.A., Grossmann, I.E., 1986. Simultaneous optimization and heat integration of chemical processes. AIChE J. 32, 123-138. doi:10.1002/aic.690320114

Foo, D.C.Y., 2008. Flowrate targeting for threshold problems and plant-wide integration for water network synthesis. J. Environ. Manage. 88, 253-274. doi:10.1016/j.jenvman.2007.02.007

Ibrić, N., Ahmetović, E., Kravanja, Z., 2016. Mathematical programming synthesis of non-isothermal water networks by using a compact/reduced superstructure and an MINLP model. Clean Technol. Environ. Policy 18, 1779-1813. doi:10.1007/s10098-016-1152-9

Ibrić, N., Ahmetović, E., Kravanja, Z., 2014. Two-step mathematical programming synthesis of pinched and threshold heat-integrated water networks. J. Clean. Prod. 77, 116-139.

Karuppiah, R., Grossmann, I.E., 2006. Global optimization for the synthesis of integrated water systems in chemical processes. Comput. Chem. Eng. 30, 650-673. doi:10.1016/j.compchemeng.2005.11.005

Kermani, M., Kantor, I.D., Maréchal, F., 2016a. Combined Water and Energy Integration in Industrial Processes with Restricted Connections, in: Proceedings of The 2016 AiChe Annual Meeting, San Francisco, CA.

Kermani, M., Périn-Levasseur, Z., Benali, M., Savulescu, L., Maréchal, F., 2016b. A novel MILP approach for simultaneous optimization of water and energy: Application to a Canadian softwood Kraft pulping mill. Comput. Chem. Eng. (in press). doi:10.1016/j.compchemeng.2016.11.043

Klemeš, J.J., 2012. Industrial water recycle/reuse. Curr. Opin. Chem. Eng. 1, 238-245. doi:10.1016/j.coche.2012.03.010

Klemeš, J.J., Kravanja, Z., 2013. Forty years of Heat Integration: Pinch Analysis (PA) and Mathematical Programming (MP). Curr. Opin. Chem. Eng. 2, 461-474. doi:10.1016/j.coche.2013.10.003

Klemeš, J.J., Varbanov, P.S., Kravanja, Z., 2013. Recent developments in Process Integration. Chem. Eng. Res. Des. 91, 2037-2053. doi:10.1016/j.cherd.2013.08.019

Leewongtanawit, B., Kim, J.-K., 2008. Synthesis and optimisation of heat-integrated multiplecontaminant water systems. Chem. Eng. Process. Process Intensif. 47, 670-694. doi:10.1016/j.cep.2006.12.018

Majozi, T., Brouckaert, C.J., Buckley, C.A., 2006. A graphical technique for wastewater minimisation in batch processes. J. Environ. Manage. 78, 317-329. doi:http://doi.org/10.1016/j.jenvman.2005.04.026

Manan, Z.A., Tan, Y.L., Foo, D.C.Y., 2004. Targeting the minimum water flow rate using water cascade analysis technique. AIChE J. 50, 3169-3183. doi:10.1002/aic.10235

Olesen, S.G., Polley, G.T., 1996. Dealing with Plant Geography and Piping Constraints in Water 
Network Design. Process Saf. Environ. Prot. 74, 273-276. doi:10.1205/095758296528626

Rosenthal, R.E., 2015. GAMS: A User's Guide. GAMS Development Corporation, Washington, DC, USA.

Savulescu, L., Kim, J.-K., Smith, R., 2005. Studies on simultaneous energy and water minimisationPart II: Systems with maximum re-use of water. Chem. Eng. Sci. 60, 3291-3308. doi:http://doi.org/10.1016/j.ces.2004.12.036

Sinnott, R.K., Coulson, J.M., Richardson, J.F., 2005. Coulson \& Richardson's chemical engineering. Elsevier Butterworth-Heinemann, Oxford.

Varbanov, P.S., 2014. Energy and water interactions: implications for industry. Curr. Opin. Chem. Eng. 5, 15-21. doi:10.1016/j.coche.2014.03.005

Wang, Y.P., Smith, R., 1994. Wastewater minimisation. Chem. Eng. Sci. 49, 981-1006. doi:10.1016/0009-2509(94)80006-5

Yan, F., Wu, H., Li, W., Zhang, J., 2016. Simultaneous optimization of heat-integrated water networks by a nonlinear program. Chem. Eng. Sci. 140, 76-89. doi:10.1016/j.ces.2015.09.036

Yee, T.F., Grossmann, I.E., 1990. Simultaneous optimization models for heat integration-II. Heat exchanger network synthesis. Comput. Chem. Eng. 14, 1165-1184. doi:10.1016/00981354(90)85010-8

Zhou, R.-J., Li, L.-J., Dong, H.-G., Grossmann, I.E., 2012a. Synthesis of Interplant Water-Allocation and Heat-Exchange Networks. Part 1: Fixed Flow Rate Processes. Ind. Eng. Chem. Res. 51, 42994312. doi:10.1021/ie2014789

Zhou, R.-J., Li, L.-J., Dong, H.-G., Grossmann, I.E., 2012b. Synthesis of Interplant Water-Allocation and Heat-Exchange Networks. Part 2: Integrations between Fixed Flow Rate and Fixed Contaminant-Load Processes. Ind. Eng. Chem. Res. 51, 14793-14805. doi:10.1021/ie3019752 


\section{Appendix A}

A.1. Simultaneous optimisation and heat integration model (M2) (Duran and Grossmann, 1986)

Based on the pinch location method the minimum consumption of hot utility $(q h u)$ is constrained by inequalities (A.1)-(A.2). The global energy balance given by Eq.(A.3) defines the minimum consumption of cold utility $(q c u)$ for the given HRAT value.

$$
\begin{array}{rlr}
q h u & \left(\sum_{j \in C P} f c_{j} \cdot\left(\max \left(0, \text { tcout }_{j}-\left(\text { thin }_{i^{\prime}}-H R A T\right)\right)-\max \left(0, \text { tcin }_{j}-\left(\text { thin }_{i^{\prime}}-H R A T\right)\right)\right)\right) & \\
& -\left(\sum_{i \in H P} f h_{i} \cdot\left(\max \left(0, \text { thin }_{i}-\text { thin }_{i^{\prime}}\right)-\max \left(0, \text { thout }_{i}-\text { thin }_{i^{\prime}}\right)\right)\right) & \\
q h u \geq & \left(\sum_{j \in C P} f c_{j} \cdot\left(\max \left(0, \text { tcout }_{j}-\text { tcin }_{j^{\prime}}\right)-\max \left(0, \text { tcin }_{j}-\text { tcin }_{j^{\prime}}\right)\right)-\right. & \\
& \left(\sum_{i \in H P} f h_{i} \cdot\left(\max \left(0, \text { thin }_{i}-\left(\text { tcin }_{j^{\prime}}+H R A T\right)\right)-\max \left(0, \text { thout }_{i}-\left(\text { tcin }_{j^{\prime}}+H R A T\right)\right)\right)\right. & \\
q h u+ & \sum_{i \in H P} e c h_{i}=q c u+\sum_{j \in C P} e c c_{j} &
\end{array}
$$

The heat content of hot and cold streams is given by Eqs. (A.4) and (A.5).

$$
\begin{array}{ll}
e c h_{i}=f h_{i} \cdot\left(\text { thin }_{i}-\text { thout }_{i}\right) & \forall i \in H P \\
e c c_{j}=f c_{j} \cdot\left(\text { tcout }_{j}-\text { tcin }_{j}\right) & \forall j \in H C
\end{array}
$$

A smooth approximation of max operator (Biegler et al., 1997) is used in order to avoid the problem of discontinuous derivatives present in Eqs. (A.1) - (A.2) due to unknown values of flow rates and hot and cold streams inlet/outlet temperatures. 


\section{A.2. HEN synthesis model (M3)}

The following equations (A.6)-(A.26) were included in the modified HEN synthesis model (Yee and Grossmann, 1990). The model used for the HEN synthesis is based on the assumption of isothermal mixing within the HEN stage-wise superstructure. This assumption can be relaxed but this would additionally increase the complexity of the model. Note that heat capacity flow rates and streams inlet/outlet temperatures are variables compared to the original model where they are parameters.

Total energy exchanged by hot stream $i$ and cold stream $j$ :

$$
\begin{array}{lrl}
f h_{i} \cdot\left(\text { thin }_{i}-\text { thout }_{i}\right)=\sum_{j \in C P} \sum_{k \in S T} q_{i, j, k}+q c_{i} & i \in H P \\
f c_{j} \cdot\left(\text { tcout }_{j}-\text { tcin }_{j}\right)=\sum_{i \in H P} \sum_{k \in S T} q_{i, j, k}+q h_{j} & j \in C P
\end{array}
$$

Energy exchanged by hot stream $i$ and cold stream $j$ in stage $k$ :

$$
\begin{array}{ll}
f h_{i} \cdot\left(t h_{i, k}-t h_{i, k+1}\right)=\sum_{j \in C P} q_{i, j, k} & i \in H P, k \in S T \\
f c_{j} \cdot\left(t c_{j, k}-t c_{j, k+1}\right)=\sum_{i \in H P} q_{i, j, k} & j \in C P, k \in S T
\end{array}
$$

Energy exchanged by hot stream $i$ with the cold utility and cold stream $j$ with the hot utility:

$$
\begin{array}{lc}
f h_{i} \cdot\left(\text { th }_{i, N O K+1}-\text { thout }_{i}\right)=q c_{i} & i \in H P \\
f c_{j} \cdot\left(\text { tcout }_{j}-t_{i, 1}\right)=q h_{j} & j \in C P
\end{array}
$$

Supply temperature of hot and cold streams $i$ and $j$ :

$$
\begin{array}{ll}
\operatorname{thin}_{i}=\operatorname{th}_{i, 1} & i \in H P \\
\operatorname{tcin}_{j}=t c_{j, N O K+1} & j \in C P
\end{array}
$$

Feasibilities of temperatures across temperature intervals:

$$
\begin{array}{lc}
t h_{i, k} \geq t h_{i, k+1} & i \in H P, k \in S T \\
t c_{j, k} \geq t c_{j, k+1} & j \in C P, k \in S T \\
t h_{i, N O K+1} \geq \text { thout }_{i} & i \in H P \\
\text { tcout }_{j} \geq t c_{j, 1} & j \in C P
\end{array}
$$

Logical constraints for heat loads:

$$
q_{i, j, k}-\min \left(e c h_{i}^{U}, e c c_{j}^{U}\right) \cdot z_{i, j, k} \leq 0 \quad i \in H P, j \in C P, k \in S T
$$




$$
\begin{array}{ll}
q c_{i}-e c h_{i}^{U} \cdot z c u_{i} \leq 0 & i \in H P \\
q h_{j}-e c c_{j}^{U} \cdot z h u_{j} \leq 0 & j \in C P
\end{array}
$$

Logical constraints for temperature differences:

$$
\begin{array}{ll}
\Delta t_{i, j, k} \leq t h_{i, k}-t c_{j, k}+\Gamma \cdot\left(1-z_{i, j, k}\right) & i \in H P, j \in C P, k \in S T \\
\Delta t_{i, j, k+1} \leq t h_{i, k+1}-t c_{j, k+1}+\Gamma \cdot\left(1-z_{i, j, k}\right) & i \in H P, j \in C P, k \in S T \\
\Delta t h u_{j} \leq t \text { huout }-t c_{j, 1} & j \in C P \\
\Delta t c u_{i} \leq t h_{i, \text { NOK }+1}-\text { tcuout } & i \in H P
\end{array}
$$

Heat loads of hot stream $i$ and cold stream $j$ :

$$
\begin{array}{ll}
e c h_{i}=f h_{i} \cdot\left(\text { thin }_{i}-\text { thout }_{i}\right) & \forall i \in H P \\
e c c_{j}=f c_{j} \cdot\left(\text { tcout }_{j}-\text { tcin }_{j}\right) & \forall j \in C P
\end{array}
$$

\section{A3. Heat exchanger related variables and parameters}

Heat exchange areas:

$$
\begin{array}{ll}
A_{i, j, k}=\frac{q_{i, j, k}}{U_{i, j} \cdot L M T D_{i, j, k}} & i \in H P, j \in C P, k \in S T \\
A_{i, C U}=\frac{q c_{i}}{U_{i, C U} \cdot L M T D_{i, C U}} & i \in H P \\
A_{j, H U}=\frac{q h_{j}}{U_{\mathrm{j}, H U} \cdot L M T D_{j, H U}} & j \in C P
\end{array}
$$

Temperature-driving forces:

$$
\begin{aligned}
& \operatorname{LMTD}_{i, j, k}=\left[\left(\Delta t_{i, j, k} \cdot \Delta t_{i, j, k+1}\right) \cdot \frac{\left(\Delta t_{i, j, k}+\Delta t_{i, j, k+1}\right)}{2}\right]^{1 / 3} \quad i \in H P, j \in C P, k \in S T \\
& \operatorname{LMTD}_{i, C U}=\left[\left(\Delta t c u_{i} \cdot\left(\text { thout }_{i}-\text { tcuin }\right)\right) \cdot \frac{\left(\Delta t c u_{i}+\text { thout }_{i}-\text { tcuin }\right)}{2}\right]^{1 / 3} \quad i \in H P
\end{aligned}
$$

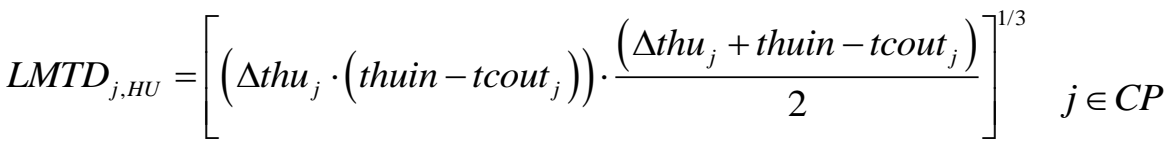

Heat transfer coefficients: 


$$
\begin{array}{ll}
\frac{1}{U_{i, j}}=\frac{1}{h_{i}}+\frac{1}{h_{j}} & i \in H P, j \\
\frac{1}{U_{i, C U}}=\frac{1}{h_{i}}+\frac{1}{h_{C U}} & i \in H P \\
\frac{1}{U_{j, H U}}=\frac{1}{h_{j}}+\frac{1}{h_{H U}} & j \in C P
\end{array}
$$

\section{A.4.Connecting equations for the combined models}

Equations (A.36)-(A.41) describe the matches of water streams within the water network model M1 with the corresponding hot and cold streams heat capacity flow rates within models M2 and M3.

Connecting equations for hot water streams

$$
\begin{array}{ll}
f h_{i}=F H S_{p} \cdot C_{p} & \forall p \in P U, i \in H P, i=p \\
\text { thin }_{i}=T H S_{p}^{(i n)} & \forall p \in P U, i \in H P, i=p \\
\text { thout }_{i}=\text { THS }_{p}^{(\text {out })} & \forall p \in P U, i \in H P, i=p
\end{array}
$$

Connecting equations for cold water streams

$$
\begin{array}{ll}
f c_{j}=F C S_{p} \cdot C_{p} & \forall p \in P U, j \in C P, j=p \\
\operatorname{tcin}_{j}=T C S_{p}^{(i n)} & \forall p \in P U, j \in C P, j=p \\
\text { tcout }_{j}=\operatorname{TCS}_{p}^{(\text {out })} & \forall p \in P U, j \in C P, j=p
\end{array}
$$

\section{A.5. Additional constraints}

By solving the model (M1-2) an initialisation point can be provided for the model (M1-3), which is solved in the second synthesis step as well as providing rigorous upper and lower bounds for freshwater and utilities consumption. The upper and lower bounds represent level values $(L V)$ of variables from the model M1-2. Eq. (A.42) is applied in the case studies involving only one water source. In addition, matches between hot and cold streams within the MINLP model are constrained with the value of the parameter $H X(i, j)$ defining the hot and cold streams within the different plants as given by Eq. (A.47)

$\sum_{s \in S F W} F W_{s} \leq \sum_{s \in S F W} F W_{s}^{L V}$

$$
|S F W|=1
$$




$$
\begin{aligned}
& \sum_{i \in H P} q c_{i} \geq q c u^{L V, H R A T \leq E M A T} \\
& \sum_{i \in H P} q h_{j} \geq q h u^{L V, H R A T \leq E M A T} \\
& \sum_{i \in H P} q c_{i} \leq q c u^{L V, H R A T \geq E M A T} \\
& \sum_{i \in H P} q c_{i} \leq q c u^{L V, H R A T \geq E M A T} \\
& z_{i, j, k} \leq H X(i, j)
\end{aligned}
$$$$
i \in H P, j \in C P, k \in S T
$$ 